\title{
Pre-Combustion Carbon Capture by a Nanoporous, Superhydrophobic Membrane Contactor Process
}

\section{DOE Contract No. DE-FE-0000646}

Reporting Period:

October 1, 2009 - March 31, 2012

Report Issued:

June 29, 2012

\section{Authors:}

Howard Meyer and S. James Zhou, GTI

Yong Ding and Ben Bikson, PoroGen Corporation

Technical Contact:

Howard Meyer (Principal Investigator)

R\&D Director

(847) 768-0955 (phone)

(847) 226-0226 (mobile)

howard.meyer@gastechnology.org

DOE Project Manager:

Dr. Arun C. Bose

Project Manager

National Energy Technology Laboratory

626 Cochrans Mill Road

P.O. Box 10940

Pittsburgh, PA 15236-094000

412-386-4467

arun.bose@netl.doe.gov

Name and Address of Submitting Organizations:

Gas Technology Institute

1700 S. Mt. Prospect Rd. PoroGen Corporation

Des Plaines, IL 60018 6C Gill St.

Woburn, MA 01801 


\section{DISCLAIMER}

This report was prepared as an account of work sponsored by an agency of the United States Government. Neither the United States Government nor any agency thereof, nor any of their employees, makes any warranty, express or implied, or assumes any legal liability or responsibility for the accuracy, completeness, or usefulness of any information, apparatus, product, or process disclosed, or represents that its use would not infringe privately owned rights. Reference herein to any specific commercial product, process, or service by trade name, trademark, manufacturer, or otherwise does not necessarily constitute or imply its endorsement, recommendation, or favoring by the United States Government or any agency thereof. The views and opinions of authors expressed herein do not necessarily state or reflect those of the United States Government or any agency thereof. 


\begin{abstract}
This report summarizes progress made during Phase I and Phase II of the project: "Pre-Combustion Carbon Capture by a Nanoporous, Superhydrophobic Membrane Contactor Process," under contract DE-FE-0000646. The objective of this project is to develop a practical and cost effective technology for $\mathrm{CO}_{2}$ separation and capture for pre-combustion coal-based gasification plants using a membrane contactor/solvent absorption process. The goals of this technology development project are to separate and capture at least $90 \%$ of the $\mathrm{CO}_{2}$ from Integrated Gasification Combined Cycle (IGCC) power plants with less than $10 \%$ increase in the cost of energy services.

Unlike conventional gas separation membranes, the membrane contactor is a novel gas separation process based on the gas/liquid membrane concept. The membrane contactor is an advanced mass transfer device that operates with liquid on one side of the membrane and gas on the other. The membrane contactor can operate with pressures that are almost the same on both sides of the membrane, whereas the gas separation membranes use the differential pressure across the membrane as driving force for separation. The driving force for separation for the membrane contactor process is the chemical potential difference of $\mathrm{CO}_{2}$ in the gas phase and in the absorption liquid. This process is thus easily tailored to suit the needs for pre-combustion separation and capture of $\mathrm{CO}_{2}$.
\end{abstract}

Gas Technology Institute (GTI) and PoroGen Corporation (PGC) have developed a novel hollow fiber membrane technology that is based on chemically and thermally resistant commercial engineered polymer poly(ether ether ketone) or PEEK. The PEEK membrane material used in the membrane contactor during this technology development program is a high temperature engineered plastic that is virtually non-destructible under the operating conditions encountered in typical gas absorption applications. It can withstand contact with most of the common treating solvents. GTI and PGC have developed a nanoporous and superhydrophobic PEEK-based hollow fiber membrane contactor tailored for the membrane contactor/solvent absorption application for syngas cleanup. The membrane contactor modules were scaled up to 8-inch diameter commercial size modules. We have performing extensive laboratory and bench testing using pure gases, simulated water-gas-shifted (WGS) syngas stream, and a slipstream from a gasification derived syngas from GTI's Flex-Fuel Test Facility (FFTF) gasification plant under commercially relevant conditions. The team have also carried out an engineering and economic analysis of the membrane contactor process to evaluate the economics of this technology and its commercial potential.

Our test results have shown that $90 \% \mathrm{CO}_{2}$ capture can be achieved with several physical solvents such as water and chilled methanol. The rate of $\mathrm{CO}_{2}$ removal by the membrane contactor is in the range of 1.5 to $2.0 \mathrm{~kg} / \mathrm{m}^{2} / \mathrm{hr}$ depending on the operating pressures and temperatures and depending on the solvents used. The final economic analysis has shown that the membrane contactor process will cause the cost of electricity to increase by $21 \%$ from the base plant without $\mathrm{CO}_{2}$ capture. The goal of $10 \%$ increase in levelized cost of electricity (LCOE) from base DOE Case 1(base plant without capture) is not achieved by using the membrane contactor. However, the $21 \%$ increase in LCOE is a substantial improvement as compared with the $31.6 \%$ increase in LCOE as in DOE Case 2(state of art capture technology using 2-stages of Selexol ${ }^{\mathrm{TM}}$ ). 
TABLE OF CONTENTS

DISCLAIMER

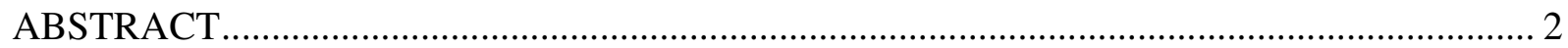

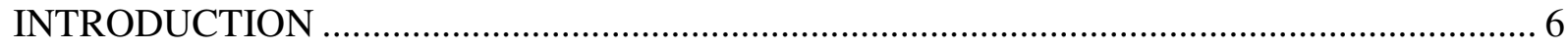

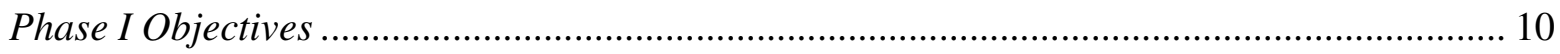

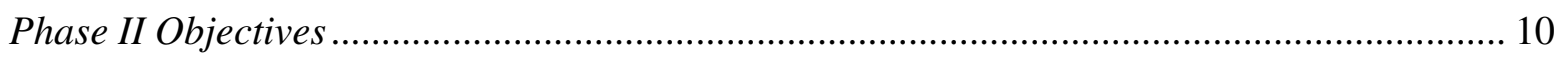

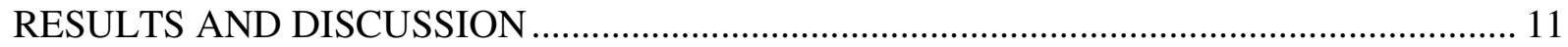

Task 1. Tailor Membrane Performance Towards $\mathrm{CO}_{2}$ Separation from Syngas ...................... 11

Subtask 1.1. Nano-porous PEEK hollow fiber substrate preparation ................................... 11

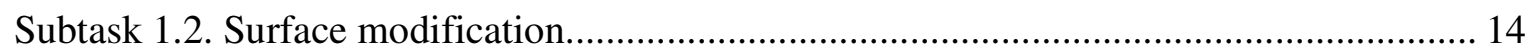

Task 2. $\mathrm{CO}_{2}$ capture testing by membrane contactor ......................................................... 16

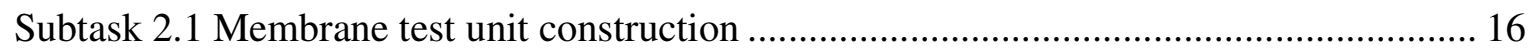

Subtask 2.2. Membrane module construction ................................................................... 18

Subtask 2.3. $\mathrm{CO}_{2}$ capture performance demonstration ....................................................... 19

Task 3. Membrane Process Design and Economic Evaluation .............................................. 21

Task 5. Membrane Contactor Manufacturing Process Scale Up ............................................ 24

Task 6. Membrane Contactor Stability and Life Testing ........................................................ 26

Task7. Bench Scale Testing of Membrane Contactors ............................................................ 30

Task 8. Bench Scale Testing Using Slipstream from GTI's FFTF Gasifier .............................. 38

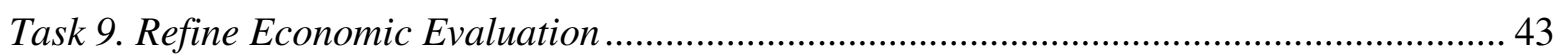

Economic Evaluation-Results and Discussion .............................................................. 44

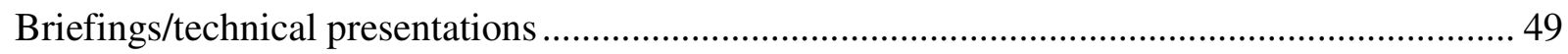

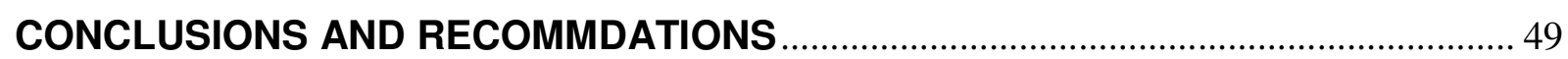

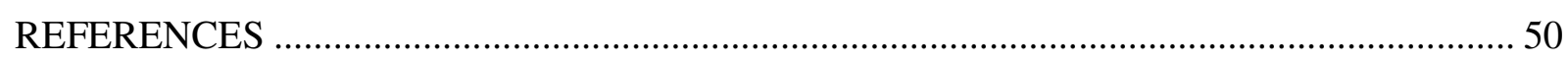

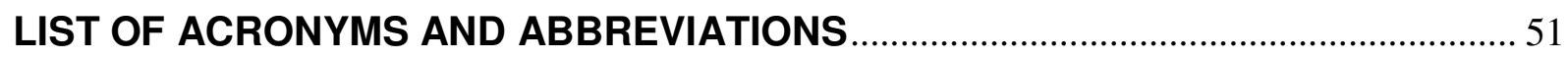

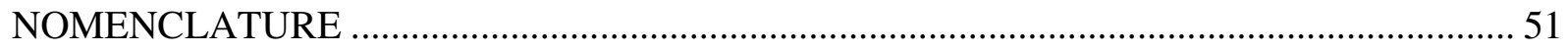




\section{EXECUTIVE SUMMARY}

During Phase I of this program, Gas Technology Institute (GTI) and PoroGen Corporation (PGC) have established the feasibility of utilizing hollow fiber membrane contactor in combination with physical solvents for gas separation applications including $\mathrm{CO}_{2}$ removal from syngas. To the extent of our knowledge, this is the first reported result of successfully utilizing membrane contactor in combination with physical solvents for $\mathrm{CO}_{2}$ separation from the syngas. The membrane contactor is based on the super-hydrophobic porous poly (ether ether ketone) (PEEK) hollow fiber membrane.

In Phase I of this program, the morphology of PEEK hollow fiber membrane and hollow fiber dimensions were modified to meet target syngas separation operation requirements. The hybrid membrane absorption process that utilizes physical solvents was developed. Membrane manufacturing procedures were transferred to commercial production equipment and bench scale modules were constructed. The modules contained circa $10 \mathrm{ft}^{2}$ of membrane area. The modules were tested for $\mathrm{CO}_{2}$ removal from mixed gas streams and the feasibility of the hybrid membrane/absorption process to remove $\mathrm{CO}_{2}$ from the syngas utilizing physical solvents was demonstrated including with Selexol® physical solvent.

Initially difficulties were encountered in using PEEK contactor in combination with Morphysorb® solvent system. The problems were traced to incompatibility of the O-ring seals with the Morphysorb® solvent system and cartridge deformation due to mild swelling of PEEK hollow fibers in an aggressive aldehyde component of the solvent system. The problems encountered were rectified by incorporating a specialty Kelrez ${ }^{\circledR}$ O-ring system and by modifying the PEEK hollow fiber spinning protocol to modify porous hollow fiber morphology to reduce solvent swelling. The initial process design and economic evaluation model were developed and were used to optimize the membrane contactor process and to enable economic evaluation.

During Phase II of this program, GTI and PGC have scaled up the process from lab to bench scale. This included scale up of the membrane module fabrication process from the 2-inch lab size modules to 8-inch commercial size modules, bench scale testing of the membrane contactor process stability and sensitivity to process variations to access membrane contactor stability and life, and slip-stream testing the membrane contactor using GTI's FFTF gasifer syngas. We have also performed refinement of the process economics based on bench test data.

Table 1. Comparison of technical goal and achieved value

\begin{tabular}{|l|l|c|c|}
\hline \multirow{2}{*}{ Parameter } & \multirow{2}{*}{ Goal } & \multicolumn{3}{|c|}{ Achieved value } \\
\cline { 3 - 4 } & & Water & Methanol \\
\hline $\mathrm{CO}_{2}$ removal in one stage & $\geq 90 \%$ & $>90 \%$ & $>90 \%$ \\
\hline $\mathrm{LCOE}$ from base DOE Case 1 & $\leq 10$ & $20.9 \%$ & $20.9 \%$ \\
\hline $\mathrm{CO}_{2}$ removal rate, $\mathrm{kg} / \mathrm{m}^{2} / \mathrm{hr}$ & & 1.5 & 2.0 \\
\hline
\end{tabular}

The completion of Phase I and II milestones is shown in Table 2. All milestones have been achieved, and as such, the objectives of Phase I and Phase II program have been met. 
Table 2. The completion of milestones

\begin{tabular}{|c|c|c|c|c|c|c|}
\hline \multirow[b]{2}{*}{$\begin{array}{c}\text { Task } \\
\text { Number }\end{array}$} & \multirow[b]{2}{*}{$\begin{array}{l}\text { Title or Brief Task } \\
\text { Description }\end{array}$} & \multicolumn{4}{|c|}{ Task Completion Date } & \multirow[b]{2}{*}{ Progress Notes } \\
\hline & & $\begin{array}{l}\text { Original } \\
\text { Planned }\end{array}$ & $\begin{array}{l}\text { Revised } \\
\text { Planned }\end{array}$ & Actual & $\begin{array}{l}\text { Percent } \\
\text { Complete }\end{array}$ & \\
\hline 1 & Issue Initial PMP & $11 / 01 / 09$ & & $10 / 29 / 09$ & 100 & \\
\hline 2 & Kickoff Meeting & $11 / 13 / 09$ & & $11 / 10 / 09$ & 100 & \\
\hline 3 & $\begin{array}{l}\text { Complete Tailor membrane } \\
\text { performance towards syngas } \\
\text { separation }\end{array}$ & $4 / 30 / 10$ & & $04 / 30 / 10$ & 100 & \\
\hline 4 & $\begin{array}{c}\text { Complete } \mathrm{CO}_{2} \text { capture testing } \\
\text { by membrane contactor }\end{array}$ & $6 / 30 / 10$ & & $06 / 30 / 10$ & 100 & \\
\hline 5 & $\begin{array}{c}\text { Complete Membrane process } \\
\text { design and economic } \\
\text { evaluation }\end{array}$ & $7 / 30 / 10$ & & 07/30/10 & 100 & \\
\hline 6 & Issue Phase I project report & $9 / 30 / 10$ & & & & \\
\hline 7 & $\begin{array}{c}\text { Complete Membrane } \\
\text { contactor manufacturing } \\
\text { process scale up }\end{array}$ & $5 / 30 / 11$ & $06 / 30 / 11$ & $06 / 30 / 11$ & 100 & \\
\hline 8 & $\begin{array}{c}\text { Complete Membrane } \\
\text { contactor stability and life } \\
\text { testing }\end{array}$ & $3 / 31 / 11$ & $12 / 31 / 11$ & $12 / 31 / 11$ & 100 & \\
\hline 9 & $\begin{array}{c}\text { Complete Bench scale testing } \\
\text { of membrane contactor }\end{array}$ & $8 / 31 / 11$ & $12 / 31 / 11$ & $12 / 31 / 11$ & 100 & \\
\hline 10 & $\begin{array}{c}\text { Complete Bench scale testing } \\
\text { with slipstream from GTI's } \\
\text { FFTF }\end{array}$ & $8 / 31 / 11$ & $12 / 31 / 11$ & $12 / 31 / 11$ & 100 & \\
\hline 11 & $\begin{array}{c}\text { Complete refine economic } \\
\text { evaluation }\end{array}$ & $8 / 31 / 11$ & $03 / 31 / 12$ & $03 / 31 / 12$ & 100 & \\
\hline 12 & Issue project final report & $9 / 30 / 11$ & $04 / 30 / 12$ & $04 / 30 / 12$ & 100 & \\
\hline
\end{tabular}




\section{INTRODUCTION}

Pre-combustion capture of $\mathrm{CO}_{2}$ from syngas offers many advantages over other means of carbon capture. The main advantage is the high efficiency of $\mathrm{CO}_{2}$ removal because the gasifier produces syngas at a higher pressure, making this $\mathrm{CO}_{2}$ capture process more efficient than post-combustion capture. The membrane contactor/solvent absorption process is one of the advanced technologies that can potentially provide an economical and technical solution for the separation and capture of $\mathrm{CO}_{2}$ from the syngas, by taking advantage of benefits of both technologies membranes and physical solvent absorption.

\section{Pre-Combustion Capture Pathway IGCC Power Plant with $\mathrm{CO}_{2}$ Scrubbing}

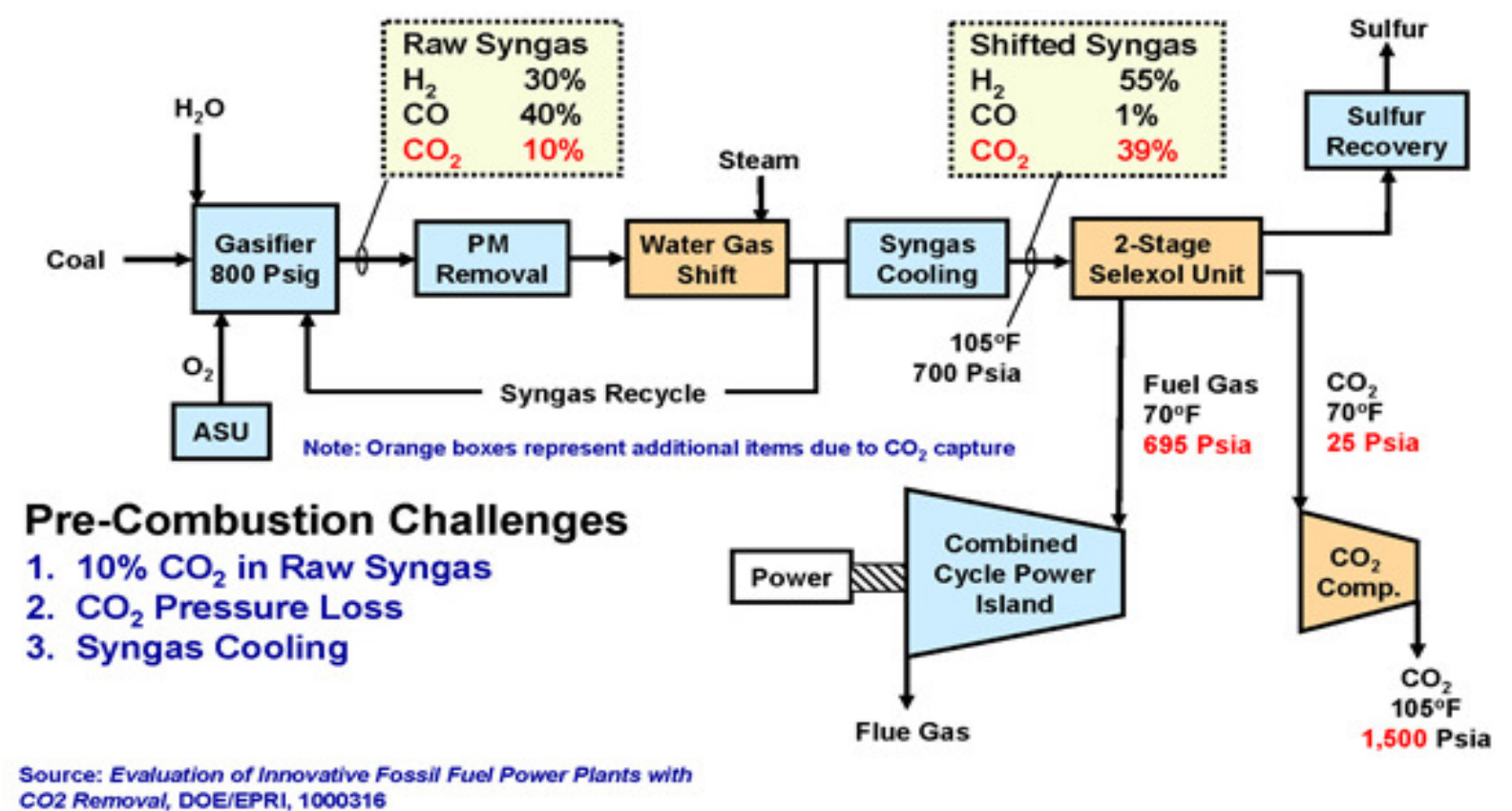

Figure 1. Pre-Combustion Carbon Capture for IGCC

The current state of the art pre-combustion carbon capture technology is the glycol-based solvent absorption process called Selexol ${ }^{\mathrm{TM}}$ process. Two stages of Selexol ${ }^{\mathrm{TM}}$ absorption units are employed after steps of water gas shift and syngas cooling to remove $\mathrm{H}_{2} \mathrm{~S}$ and capture $\mathrm{CO}_{2}$ as shown in Figure 1 above. Analysis conducted at NETL shows that $\mathrm{CO}_{2}$ capture and compression using Selexol raises the cost of electricity from a newly built IGCC power plant by 30 percent, from an average of 7.8 cents per kilowatt-hour to 10.2 cents per kilowatt-hour ${ }^{2}$.

GTI and PGC have developed a new PEEK material's based membrane contactor that can be used in a membrane contactor/solvent absorption process for the pre-combustion separation and capture of $\mathrm{CO}_{2}$. PEEK (poly ether ether ketone) is an advanced engineering polymer superior to essentially all commercial polymers in thermo-mechanical properties and chemical resistance. The 
PEEK membrane is in the hollow fiber configuration and is produced by a patented process $\mathrm{s}^{3,4}$. Physical solvents can be used to separate and capture $\mathrm{CO}_{2}$ from syngas with the membrane as a phase boundary between the gas and the liquid due to the high partial pressure of $\mathrm{CO}_{2}$ in the syngas stream.

The membrane contactor technology is a hybrid between a membrane process and an absorption process that takes advantages of both the compact nature of the membrane process and the high selectivity of the absorption process. The contactor utilizes solvent absorption with the membrane as the phase boundary between the gas and the solvent. The process of $\mathrm{CO}_{2}$ capture from syngas using membrane contactor is shown schematically in Figure 2.

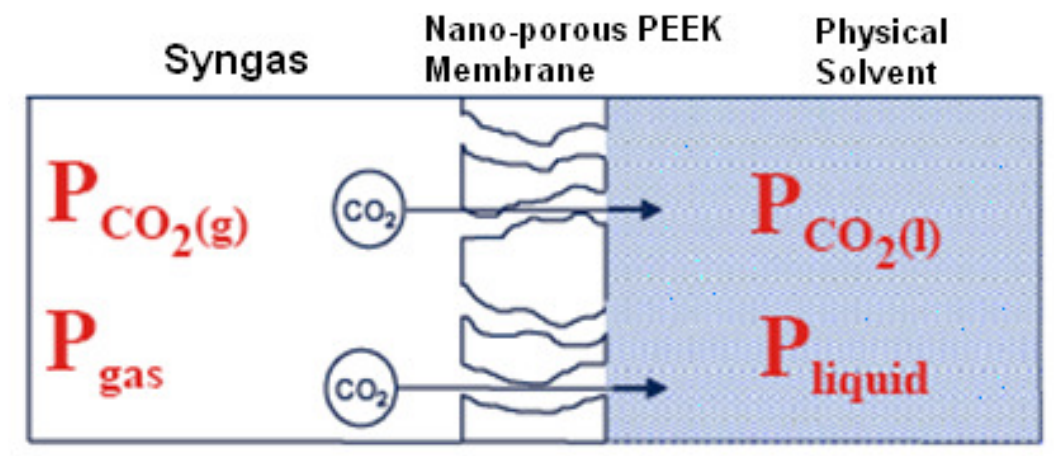

Figure 2. Schematic of the membrane contactor process.

The interfacial area is the key in enabling efficient mass transfer by directly influencing the overall mass transfer of $\mathrm{CO}_{2}$ from the gas into the solvent and thus the size of the processing equipment. In this project, the interfacial area has been increased by an order of magnitude over a conventional packed or trayed column by using novel hollow fiber configuration in the contactors. Hollow fiber configuration allows for a high membrane surface area per unit volume and results in a much more compact absorption system of a dramatically reduced size and weight.

In this project the membrane contactors were constructed from the superhydrophobic PEEK hollow fiber membranes that constitute the novel, enabling feature of the technology. The hollow fiber membrane is exceptionally hydrophobic with a water breakthrough pressure greater than 100 psig. The technology has been developed by PGC and commercialized for several gas transfer applications including solvent based systems. The PEEK hollow fiber contactor is ideally suited for $\mathrm{CO}_{2}$ capture from syngas since the pressures on the bore side and the shell side can be maintained independently at different levels, which is not possible for conventional columns.

Membrane contactor vs. conventional membrane process: A conventional membrane process operates by a solution/diffusion mechanism, and the separation driving force is provided by the partial pressure difference of each component across the membrane. The main limitation of conventional membrane processes is either the process pressure ratio (feed gas pressure/ permeate gas pressure) limitation or the selectivity limitation. ${ }^{5}$

The importance of pressure ratio becomes apparent in membrane separation of a gas mixture by considering the separation of component $M$ at feed pressure $p_{f}$. A flow of component $M$ across the membrane can only occur if the partial pressure of $M$ on the feed side is greater 
than the partial pressure of $M$ on the permeate side. That is:

$$
y_{M f} p_{f} \geq y_{M p} p_{p}
$$

Thus, the maximum separation achieved by the membrane can be expressed as:

$$
\frac{p_{f}}{p_{p}} \geq \frac{y_{M p}}{y_{M f}}
$$

where, $p_{f}$ and $p_{p}$ are the feed and permeate side pressures, $y_{M f}$ and $y_{M p}$ are mole fractions of component $\mathrm{M}$ in the feed and permeate sides, respectively. Equation (2) simply illustrates that the enrichment achievable in the permeate relative to the feed $\left(y_{M P} / y_{M f}\right)$ is always less than the feed-to-permeate pressure ratio $\left(p_{f} / p_{p}\right)$, no matter how selective the membrane. In practical gas separation applications, the pressure ratio across the membrane is usually between 5 and $15 .{ }^{6} \mathrm{An}$ example of pressure ratio and selectivity limitation cases is shown in Figure 3 . The concentration of $\mathrm{M}$ in the feed is $1 \mathrm{~mol} \%$. Below pressure ratios of ca. 10, separation is limited by the pressure ratio across the membrane, while at pressure ratios above ca.100, separation is limited by the membrane selectivity. ${ }^{5}$

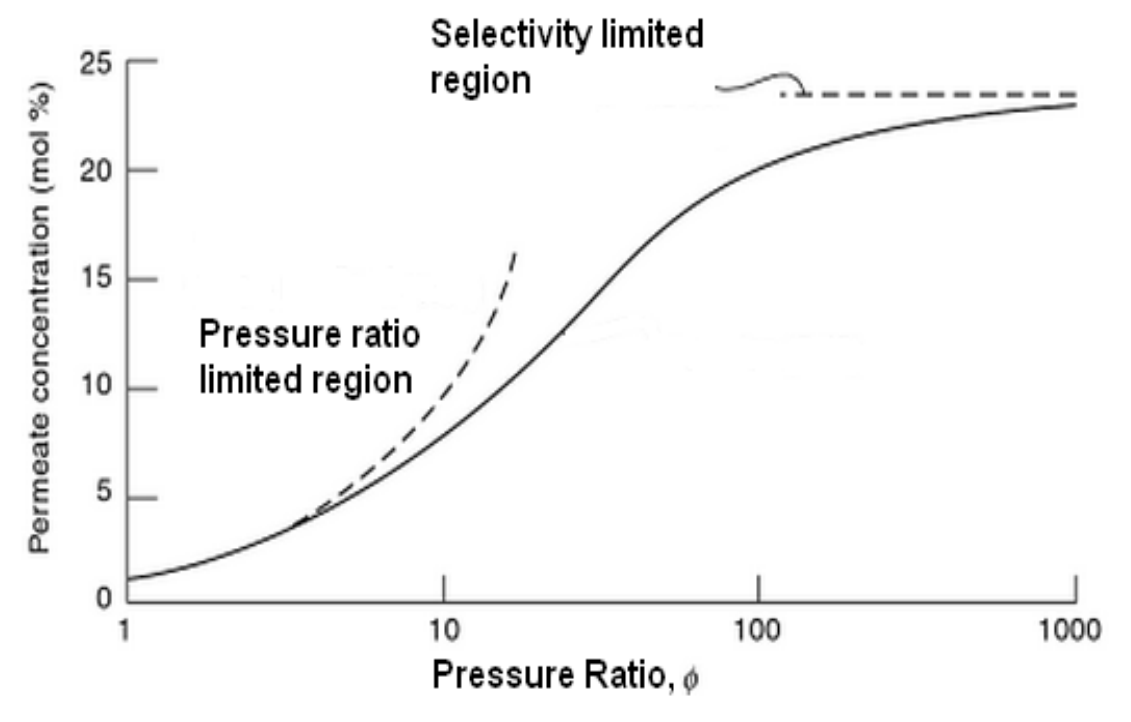

Figure 3. Calculated permeate concentration of the "more permeable" components, $M$, as a function of pressure ratio (membrane selectivity, $\alpha_{M / N}=30$ ).

When the membrane separation process is pressure ratio limited, the product $\mathrm{CO}_{2}$ concentration will be limited even when the membrane selectivity is much larger than the pressure ratio. In contrast, the hybrid membrane/absorption process is not limited by the pressure ratio and high purity of $\mathrm{CO}_{2}$ product can be generated in a single stage. The process selectivity for the hybrid membrane/absorption process is determined by the physical and chemical affinity of the absorption solvent to $\mathrm{CO}_{2}$. 
Mass transfer coefficient for membrane contactor: The transport of carbon dioxide through a membrane contactor is shown in Figure 4. $C_{g}, C_{g m}, C_{m l}, C_{l m}$ and $C_{l}$ are the $\mathrm{CO}_{2}$ concentration in the gas phase, at the gas-membrane interface, at the membrane-liquid interface, at the liquid-membrane interface and in the liquid.

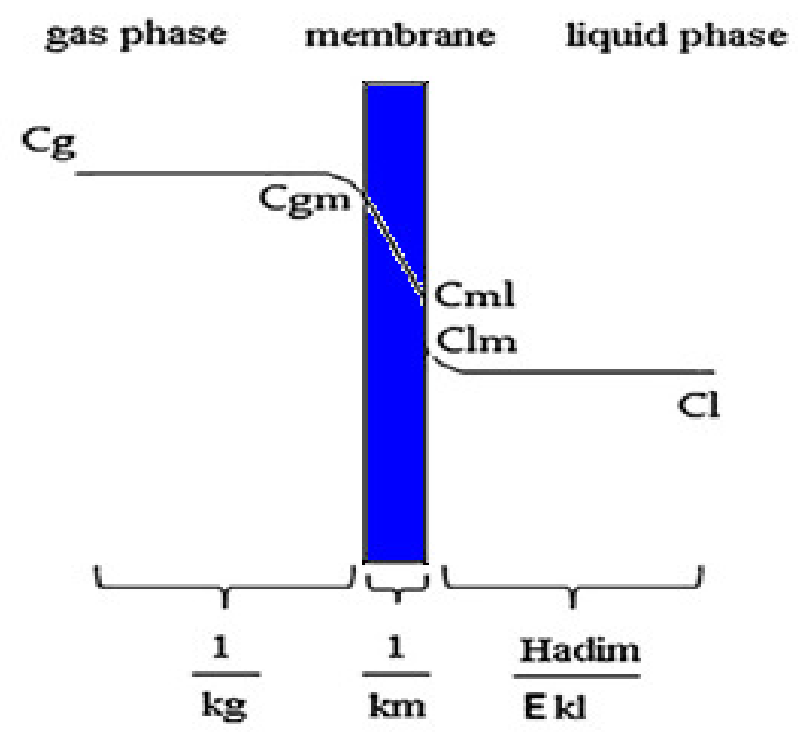

Figure 3. $\mathrm{CO}_{2}$ concentration profile and resistance in series model in a membrane contactor.

The $\mathrm{CO}_{2}$ mass transfer coefficient for a gas-liquid absorption process can be expressed as follows:

$$
\frac{1}{K}=\frac{1}{k_{g}}+\frac{1}{k_{m}}+\frac{H_{\text {adim }}}{E \cdot k_{l}}
$$

Where $K$ is the overall mass transfer coefficient [cm/s], $k_{g}$ is the mass transfer coefficient in the gas phase, $k_{m}$ is the mass transfer coefficient in the membrane [cm/s], $k_{l}$ is the mass transfer coefficient in the liquid phase [cm/s], $H_{\text {adim }}$ is the non-dimensional Henry's constant, and $E$ is the enhancement factor due to chemical reaction. In case of physical solvent, there is no chemical reaction and the enhancement factor $\mathrm{E}$ is unity.

The overall resistance to $\mathrm{CO}_{2}$ transport and the overall mass transfer coefficient have an inverse relationship. To maximize the mass transfer coefficient, the overall resistance must be reduced, which in turn entails reducing resistance of individual components contributing to the overall resistance. The resistance in the gas phase is typically very small and the resistance in the membrane phase is a function of membrane structure. The resistance in the liquid phase is a function of contactor module design, i.e. flow dynamics, and solvent characteristics.

\section{OBJECTIVES}

The overall objective of this project was to develop a practical and cost effective technology for $\mathrm{CO}_{2}$ separation and capture for pre-combustion coal-based gasification plants using the membrane contactor/solvent absorption process. The goals of this technology development project are to separate and capture at least $90 \%$ of the $\mathrm{CO}_{2}$ from Integrated Gasification Combined 
Cycle (IGCC) power plants with less than $10 \%$ increase in the cost of energy service. The project was divided into two phases and their respective objectives are shown below.

\section{Phase I Objectives}

Phase I work concentrates on the development of the hollow fiber membranes suitable for the membrane contactor application with improved mass transfer. The other objectives of Phase I work include establishing feasibility of the membrane contactor technology for syngas $\mathrm{CO}_{2}$ separation, performing process design, and economic analysis based on test data. The work plan consists of following tasks:

\section{Table 3. Phase 1 tasks}

\begin{tabular}{|c|c|c|c|}
\hline $\begin{array}{c}\text { Task } \\
\#\end{array}$ & Task Title & $\begin{array}{c}\text { Estimated Completion } \\
\text { (months from award) }\end{array}$ & $\begin{array}{c}\text { Responsible } \\
\text { Individual/Organization }\end{array}$ \\
\hline 1 & $\begin{array}{c}\text { Tailor membrane performance } \\
\text { towards syngas separation }\end{array}$ & 7 & $\begin{array}{c}\text { Research Scientist } \\
\text { PGC }\end{array}$ \\
\hline 2 & $\begin{array}{c}\mathrm{CO}_{2} \text { capture testing by membrane } \\
\text { contactor }\end{array}$ & 9 & $\begin{array}{c}\text { Research Scientists } \\
\text { GTI and PGC }\end{array}$ \\
\hline 3 & $\begin{array}{c}\text { Membrane process design and } \\
\text { economic evaluation }\end{array}$ & 10 & $\begin{array}{c}\text { Research Scientists GTI and } \\
\text { PGC }\end{array}$ \\
\hline 4 & Phase I project management & 12 & GTI and PGC PI \\
\hline
\end{tabular}

\section{Phase II Objectives}

The objectives of Phase II work is to scale up the process from lab to bench scale. This includes scale up of the membrane module fabrication process so that membrane modules of the size suitable for large scale application can be manufactured; bench scale testing of the membrane contactor process stability and sensitivity to process variations; and membrane contactor stability and life. The other objectives of Phase II work is refinement of the process economics based on bench test data.

In Phase II of this program the manufacture of the membrane contactor was scaled up, the process for $\mathrm{CO}_{2}$ capture from syngas developed, and bench tests conducted. Extensive bench testing with simulated syngas at GTI's gas/liquid membrane contactor testing units was conducted with flows up to 0.15 MMscfd. Testing with a slipstream from GTI's Flex Fuel Test Facility, or FFTF, gasifier was conducted. The work plan consists of following tasks:

Table 4. Phase 2 tasks

\begin{tabular}{|c|c|c|c|}
\hline $\begin{array}{c}\text { Task } \\
\#\end{array}$ & Task Title & $\begin{array}{c}\text { Estimated Completion } \\
\text { (months from award) }\end{array}$ & $\begin{array}{c}\text { Responsible } \\
\text { Individual/Organization }\end{array}$ \\
\hline 5 & $\begin{array}{c}\text { Membrane contactor manufacturing } \\
\text { process scale up }\end{array}$ & 20 & $\begin{array}{c}\text { Research Scientist } \\
\text { PGC }\end{array}$ \\
\hline 6 & $\begin{array}{c}\text { Membrane contactor stability and life } \\
\text { testing }\end{array}$ & 18 & $\begin{array}{c}\text { Research Scientists } \\
\text { GTI and PGC }\end{array}$ \\
\hline 7 & $\begin{array}{c}\text { Bench scale testing of membrane } \\
\text { contactor }\end{array}$ & 23 & Research Scientists GTI \\
\hline 8 & $\begin{array}{c}\text { Bench scale testing with slipstream } \\
\text { from GTI's FFTF }\end{array}$ & 23 & GTI Engineers \\
\hline 9 & \begin{tabular}{c} 
Refine economic evaluation \\
\hline
\end{tabular}
\end{tabular}




\begin{tabular}{|c|c|c|c|}
\hline 10 & Phase II project management & 24 & GTI and PGC PI's \\
\hline
\end{tabular}

\section{RESULTS AND DISCUSSION}

All work outlined above was completed by GTI and PGC. The results are summarized in the following sections. We have successfully completed the PEEK hollow fiber membrane contactor technology development work, demonstrated the feasibility of scaling up the membrane module production process for fabrication of commercial size modules, performed extensive laboratory and bench testing using pure gas, simulated syngas stream, and a slipstream from a biomass gasification derived syngas from GTI's Flex-Fuel Test Facility (FFTF) gasification plant. The team also carried out an engineering and economic analysis of the membrane contactor process for syngas carbon capture.

\section{Task 1. Tailor Membrane Performance Towards $\mathrm{CO}_{2}$ Separation from Syngas}

Description of Work: In this task hollow fiber membrane for membrane contactor with properties tailored towards syngas treatment were developed. The membrane consisted of nano-porous PEEK hollow fiber with graft perfluoropolymer surface layer.

The hollow fiber membranes were manufactured from the best in class commercial engineering plastic, PEEK. Porous PEEK hollow fibers (small diameter porous tubes, circa 500 micron outside diameter and 250 micron inside diameter) used in preparation of super-hydrophobic membranes were manufactured by a high temperature melt extrusion process. The process is used commercially by PGC to prepare fluid separation membranes. PGC manufactures porous PEEK hollow fibers from blends of PEEK polymer with porogens such as polyether imide (PEI) following procedures described in US Patent 6,887,408 assigned to PGC. The process is illustrated schematically in Figure 4.

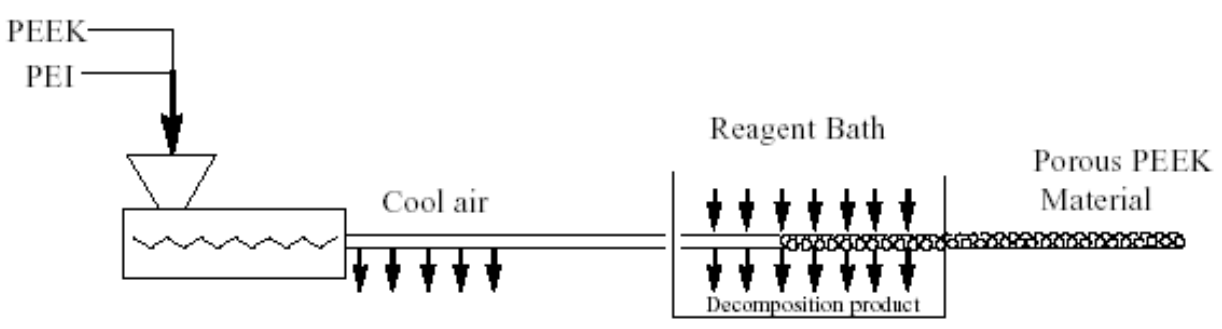

Figure 4. Process for the preparation of nanoporous PEEK materials (reagent bath monoethanolamine)

\section{Subtask 1.1. Nano-porous PEEK hollow fiber substrate preparation}

The pore size and pore volume of the PEEK hollow fiber substrates was optimized towards preparation of membrane with high $\mathrm{CO}_{2}$ permeability.

Project Activities/Products: The PEEK hollow fiber morphology was optimized for the target application. Optimization of porous hollow fiber preparation procedures was carried out by varying the processing conditions in the spinning line. It has been found that the processing conditions have a significant effect on the fiber performance in contact with physical solvents. Although hollow fibers are solvent stable in all solvents tested, some small degree of swelling can occur with the most aggressive solvents leading to the deformation in the hollow fiber cartridge 
that in turn can result in cartridge failure. Processing conditions at low temperatures resulted in hollow fiber membranes with higher levels of swelling in physical solvents. Optimum processing conditions have been identified with the resulting fiber, exhibiting good dimensional stability in contact with organic physical solvents. The experimental variables included the precursor blend composition, spinning temperature profile, extruder screw design, spinning speed, and draw ratio. The following (PEEK/PEI) blend compositions were evaluated 40/60, 45/55 and 50/50 (weight ratios). The fiber take up speeds varied from 100 to $1000 \mathrm{ft} / \mathrm{min}$.

PEEK is a semi-crystalline polymer and it is critical to maximize the degree of crystallization to obtain optimal mechanical, thermal, and chemical resistance characteristics. The processing conditions were optimized to attain degree of crystalinity of about $34 \%$ in porous PEEK hollow fibers that is similar to the virgin PEEK material. PEEK/PEI blends can form spherulitic or lamellar morphologies that can affect final pore structure as shown in Figure 5.
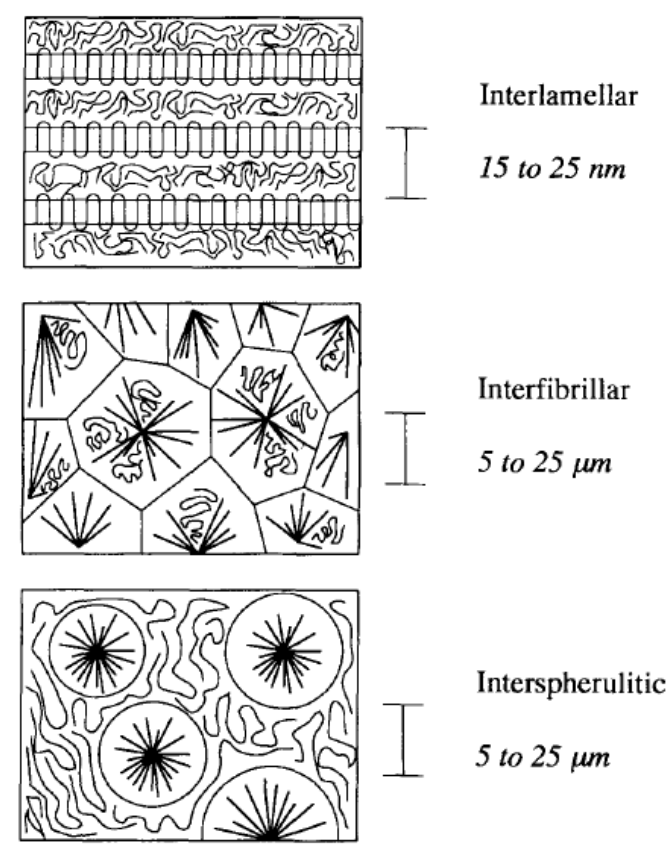

Figure 5. PEEK/PEI blend morphologies

Significant orientation of lamellar morphology occurs during spinning with increase in draw ratio as shown in Figure 6. 


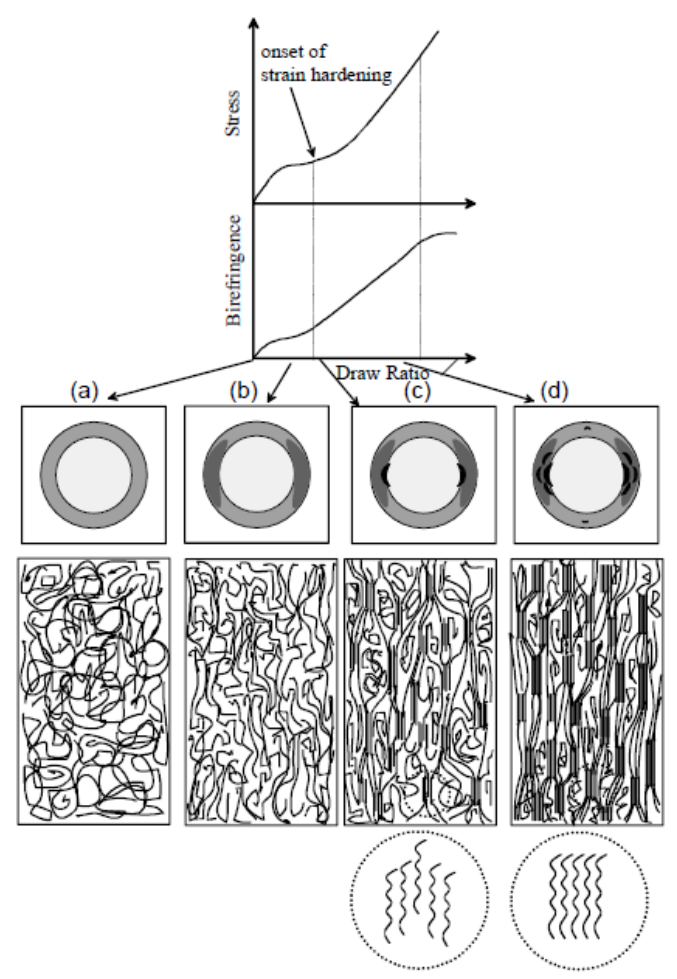

Figure 6. Uniaxial deformation during spinning process

The processing conditions were systematically varied to obtain fiber morphology tailored towards contact with physical solvents (stability and non-wetting). The fiber compatibility with physical solvents is discussed below. The morphology of a typical porous PEEK hollow fiber is shown in Figure 7.
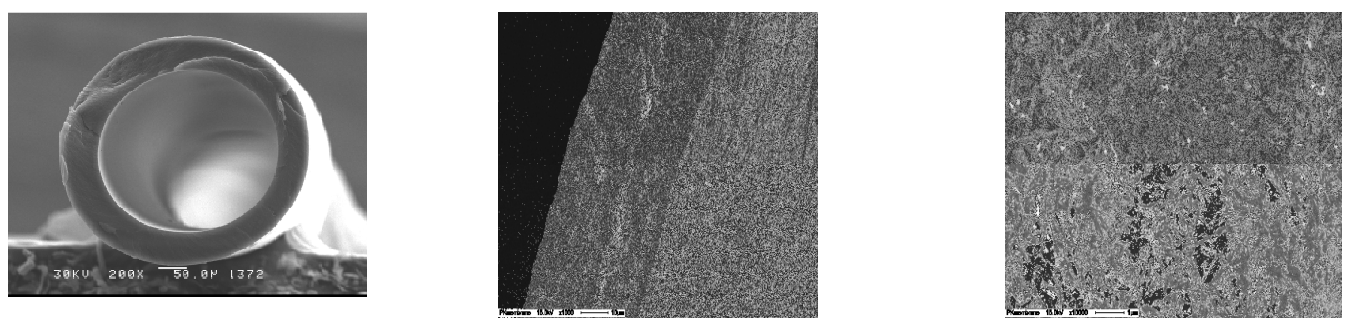

Figure 7. Porous PEEK hollow fiber substrate cross-section, OD/ID 18/15 mil, average pore size $12 \mathrm{~nm}$

The nano-porous PEEK hollow fiber substrates developed for the contactor application exhibit very high gas permeation rates, which is a critical feature for preparation of high flux membranes. The gas permeance $\left(\mathrm{O}_{2}, \mathrm{~N}_{2}\right.$, and $\left.\mathrm{CO}_{2}\right)$ of a typical hollow fiber with 100 micron thick porous wall exceeds $5000 \mathrm{GPU}\left[1 \mathrm{GPU}=1 \times 10^{-6} \mathrm{~cm}^{3}(\mathrm{STP}) /\left(\mathrm{cm}^{2} \cdot \mathrm{s} \cdot \mathrm{cmHg}\right)\right]$.

In further development, nano-porous PEEK hollow fibers were prepared with asymmetric pore morphology, i.e. smaller diameter surface pores $(1-5 \mathrm{~nm})$ and larger size interior pores (12-15 $\mathrm{nm})$. The surface layer with the smaller size pores was about 1 micron thick. The asymmetric structure enables preparation of super-hydrophobic membranes with improved non-wetting

DE-FE-0000646 Final Technical Report 
characteristics while maintaining high gas permeance. Hollow fibers with nanometer size surface pores are expected to exhibit Knudsen flow characteristics (gas flux is inversely proportional to the square root of the molecular weight) consistent with 1-5 nm size surface pores. Asymmetric PEEK hollow fibers in fact did exhibited gas separation factors consistent with the theoretic Knudsen flow.

The porous structure of hollow fiber surface was examined by Atomic Force Microscopy and by Electron Scanning Microscopy. The surface porosity of a typical PEEK hollow fiber is shown in Figures 8 and 9.

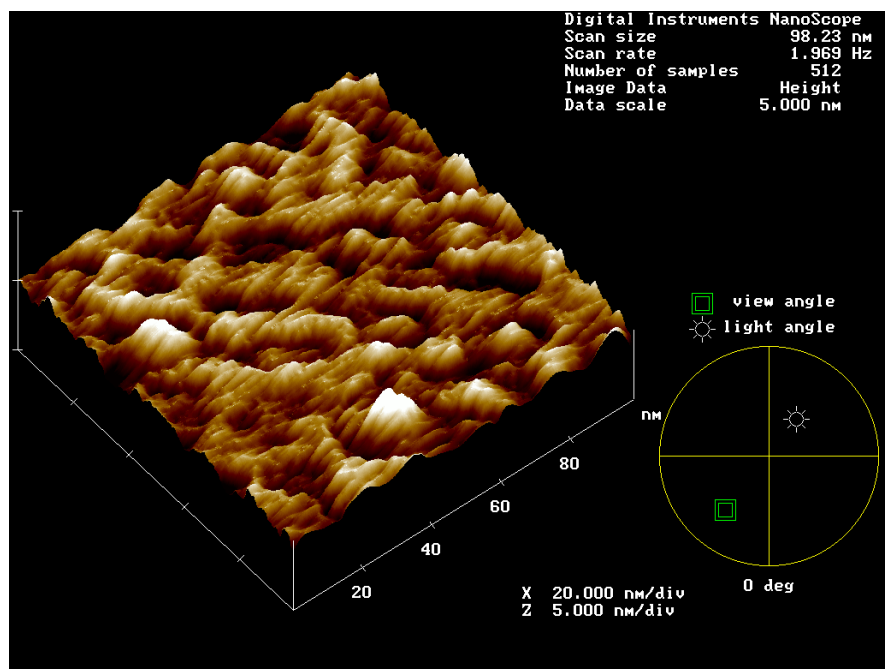

Figure 8. Atomic force microscopy analysis of PEEK hollow fiber surface

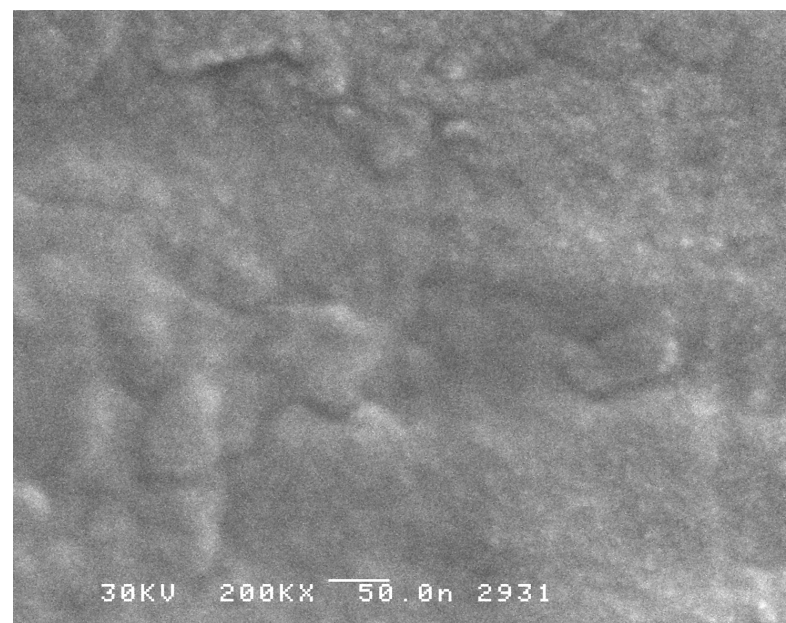

Figure 9. SEM microphotograph of PEEK hollow fiber surface at magnification of $200,000 \mathrm{X}$

\section{Subtask 1.2. Surface modification}

Description of Work: In this subtask, the porous PEEK hollow fibers with graft perfluoro-hydrocarbon surface were prepared. The superhydrophobicity of the porous PEEK membrane was generated by surface modification with a functional perfluoro oligomer, such as PFC 504A/coE5 (containing epoxide reactive groups), commercially available from Cytonix 
Corporation. The hollow fiber membrane morphology and surface chemistry were optimized to maximize $\mathrm{CO}_{2}$ permeance while minimizing solvent intrusion.

Project Activities/Products: The hollow fibers developed in Subtask 1.1 were treated to generate super-hydrophobisity. Surface modification was carried out following procedures developed by PGC.

The PEEK is rendered super-hydrophobic (oleophobic) by surface modification. The surface of the porous PEEK is rendered oleophobic (non-wetting) by treatment with functional perfluoro oligomers. Prior to grafting with perfluoro oligomers the surface of the porous PEEK membrane is first functionalized with $\sim \mathrm{OH}$ groups by reacting ketone groups in PEEK polymer backbone with monoethanolamine. The surface of the nano-porous PEEK membrane is functionalized with hydroxyl groups by reacting ketone groups with monoethanolamine by a process shown in Figure 10. Since monoethanolamine is also used to form the porous PEEK material as shown in Figure 4 [US Patents 6,887,408 and 7,176,273 issued to PGC] both processes are combined to obtain surface modified porous PEEK membranes in a single step.

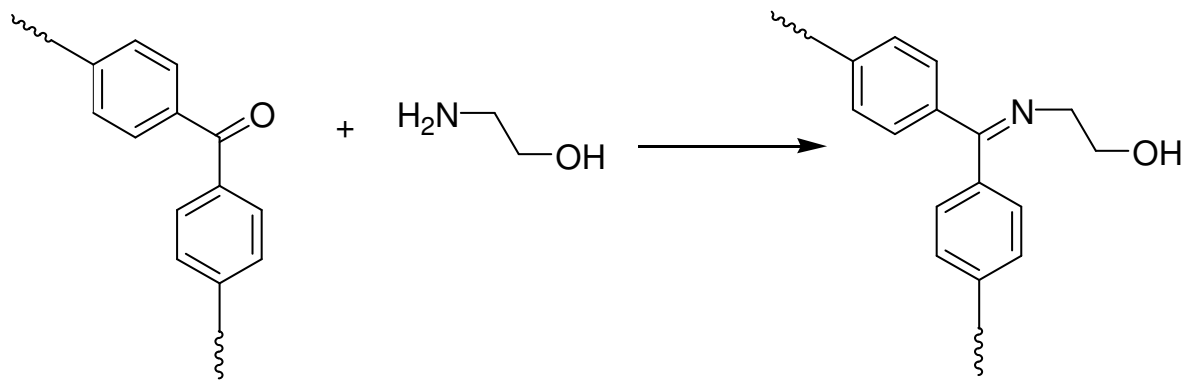

Figure 10. Surface functionalization of porous PEEK with OH groups during preparation of porous PEEK hollow fiber

The hydroxyl groups are utilized as the anchor points for the subsequent grafting reaction with functional perfluoro hydrocarbon oligomer to render the pore surfaces oleophobic. The functional $\sim \mathrm{OH}$ groups are reacted with functional hydrophobic oligomers to form a hydrophobic graft surface. The grafting reaction with perfluorinated oligomer is illustrated schematically in Figure 11.

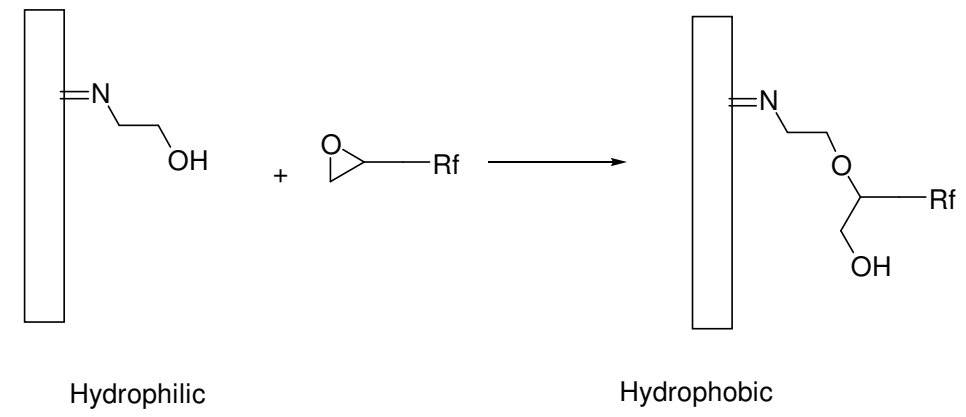

Figure 11. Preparation of hydrophobic PEEK membranes ( $R f$ is a perfluoro hydrocarbon radical)

Porous PEEK membranes are super-hydrophobic and do not wet out in contact with solvent systems. Porous PEEK membranes wet out with water at pressure above 100 psig and with isopropanol (IPA) at pressure above 20 psig. The super-hydrophobicity is due to a combination of 
nanometer size surface pores, exceptionally uniform pore size distribution, and the perfluoro-hydrocarbon surface chemistry. The surface pore diameter is in the range of 1 to $5 \mathrm{~nm}$. The combination of nanometer size pores and perfluoro-hydrocarbon surface chemistry generate the super-hydrophobicity via so called "Lotus effect". The high contact angle of and the non-wetting of porous PEEK membrane surface by solvents (ethanol liquid drop) is shown in Figure 12. The ethanol does not wet the porous structure.

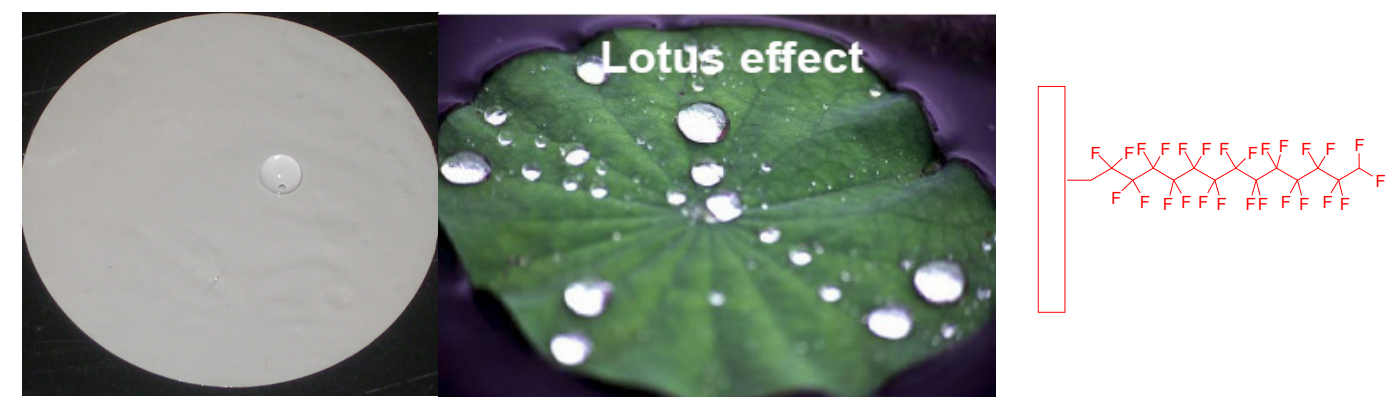

Figure 12. High contact angle and the non-wetting of porous PEEK membrane surface (ethanol liquid drop)

The membrane preparation procedure was further modified to improve non-wetting characteristics. In additional to the grafting of perfluorinated polymer surface layer, an ultra-thin (700 ̊ thick layer) dense coating layer was added to improve non-wetting characteristics. The additional layer is highly $\mathrm{CO}_{2}$ permeable and did not increase membrane resistance measurably.

\section{Task 2. $\mathrm{CO}_{2}$ capture testing by membrane contactor}

\section{Subtask 2.1 Membrane test unit construction}

Description of Work: In this subtask, a laboratory test unit that allowed for the evaluation of $\mathrm{CO}_{2}$ separation performance by membrane contactor equipped with PEEK hollow fiber membranes was constructed. Water vapor saturated, carbon dioxide-nitrogen gas mixtures were utilized initially as a simulated syngas feed composition representing the coal-derived syngas downstream of the WGS. The test unit was used to support membrane development initially by testing contactor performance at commercially relevant process conditions.

Project Activities/Products: The construction work was completed and the test unit was put into operation under the appropriate test conditions for syngas carbon capture. Simplified test unit schematic is presented in Figure 13 below without details of valves and pressure regulators. A photo of the test unit is shown in Figure 14.

The test unit is designed to operated at pressures up to $1000 \mathrm{psig}$, at gas flow rates up to 0.5 MMSCFD, and at liquid flow rates up to $1 \mathrm{~L} / \mathrm{min}$. The membrane contactor can be mounted vertically or horizontally. 


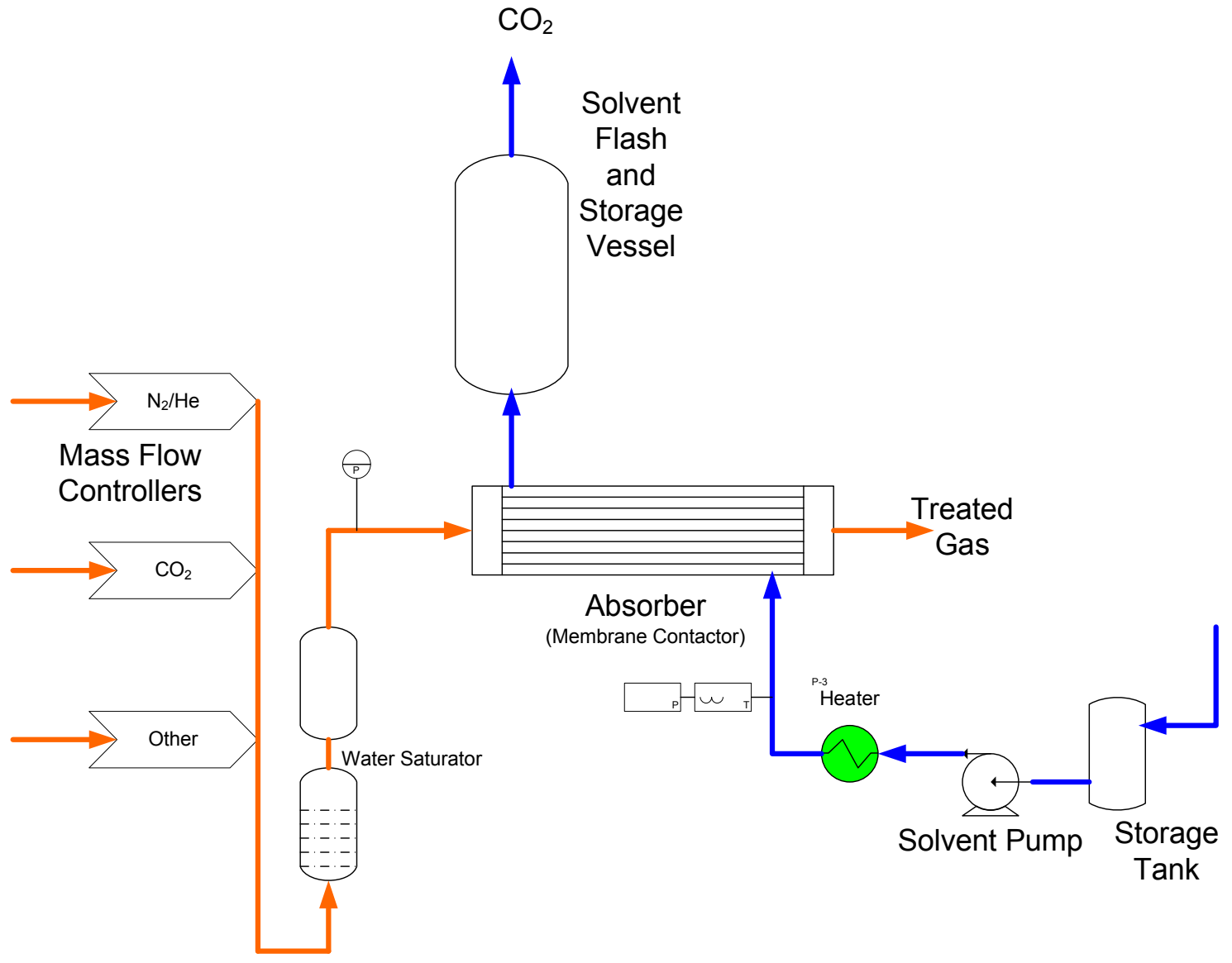

Figure 13. Simplified Membrane Contactor Test Unit Schematics

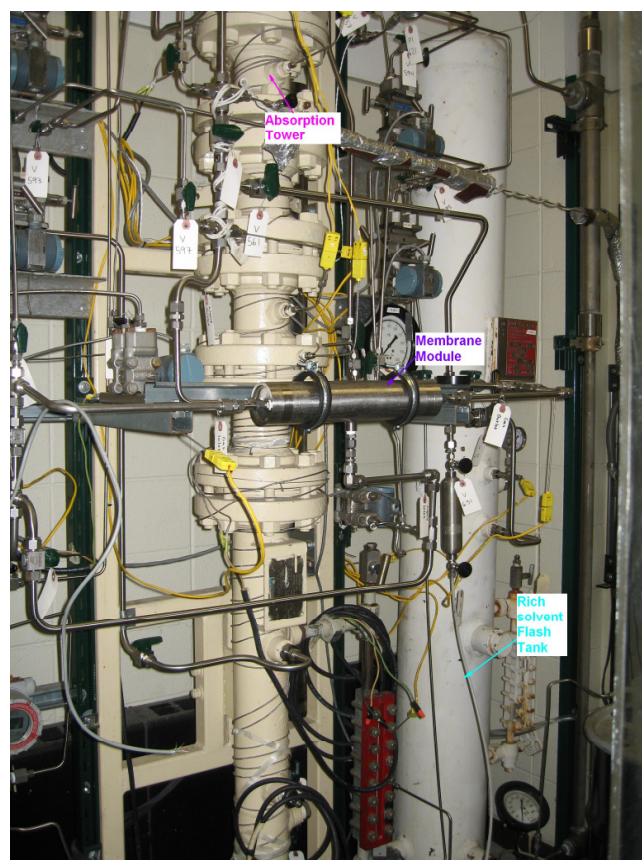

Figure 14. Picture of the membrane test unit.

DE-FE-0000646 Final Technical Report 


\section{Subtask 2.2. Membrane module construction}

Description of Work: In this subtask, membrane modules for bench scale tests were prepared. The hollow fiber membrane module design was of the four port configuration. The hollow fiber cartridge was formed by computer-controlled helical winding. The cartridge size was 2" diameter by 12 " long and contained about 10 to $20 \mathrm{ft}^{2}$ of membrane area (the area measured on the outside diameter of hollow fibers). The cartridge was housed in a pressure vessel sufficient to operate at gasifier pressures of up to $1000 \mathrm{psig}$.

Project Activities/Products: We have used an advanced module construction methodology ensuring the optimal flow distribution and maximization of membrane separation efficiency. The hollow fiber placement within the module was controlled through computer controlled helical fiber winding. The process generates a structured packing configuration minimizing channeling, bypassing, and minimizing concentration polarization. A wound cartridge with a controlled uniform structured packing is shown in Figure 15. The hollow fibers are arranged in a helical path, with the axis of the fibers running confluent to the principle direction of fluid flow. To enable the thermodynamically most efficient counter-current flow, the packing density in the cartridge must be uniform. Also, flow bypassing, and entrance and exit effects must be minimized. The fiber packing density and packing uniformity was controlled to ensure an optimal flow distribution with minimal pressure drop on both the feed and the permeate sides. These parameters were further optimized in Phase 2 of the program by theoretic modeling and experimentally verified. The optimized design parameters were utilized to construct the bench scale membrane module.

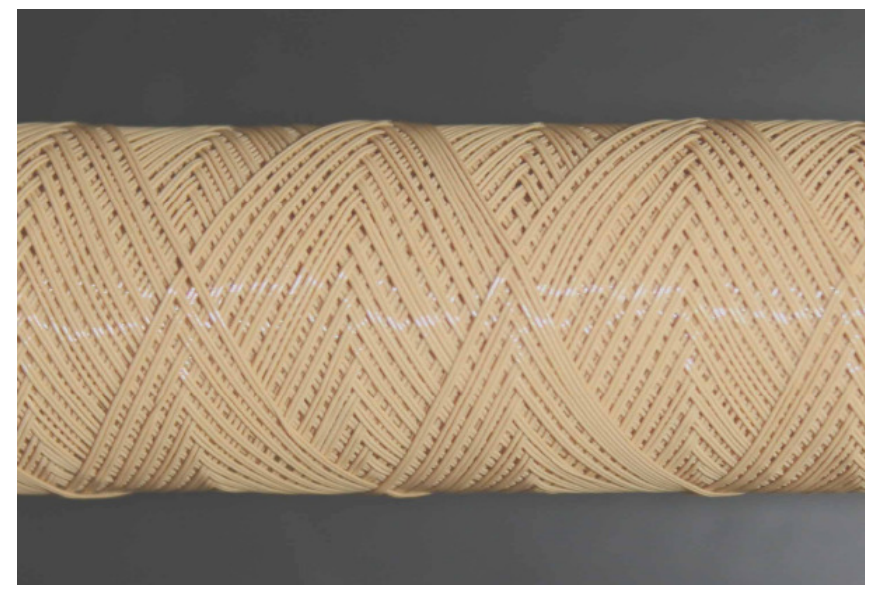

\section{Figure 15. Helically Wound Structured Hollow Fiber Cartridge}

Several two inch diameter membrane contactor modules were designed and constructed. A single 2" diameter 12" long cartridge contained circa $10 \mathrm{ft}^{2}$ of membrane surface area. The cartridge flow schematic is shown in Figure 16. The four-port design was utilized with feed gas entrance port, product gas exit port, lean physical solvent entrance, and rich physical solvent exit port. 


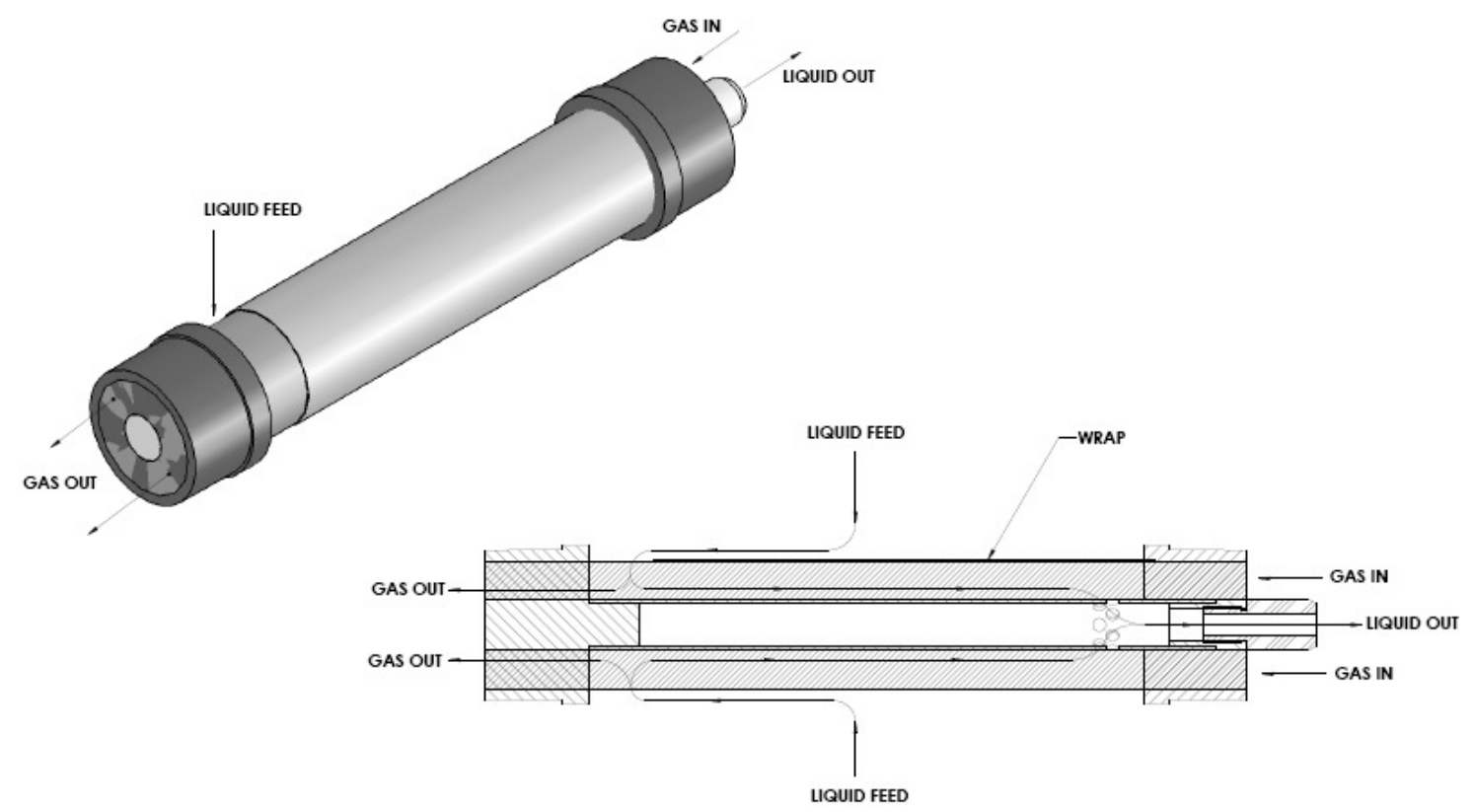

Figure 16. Flow schematics of four port hollow fiber membrane cartridge

The cartridge was installed into high-pressure stainless steel housing shown in Figure 17.

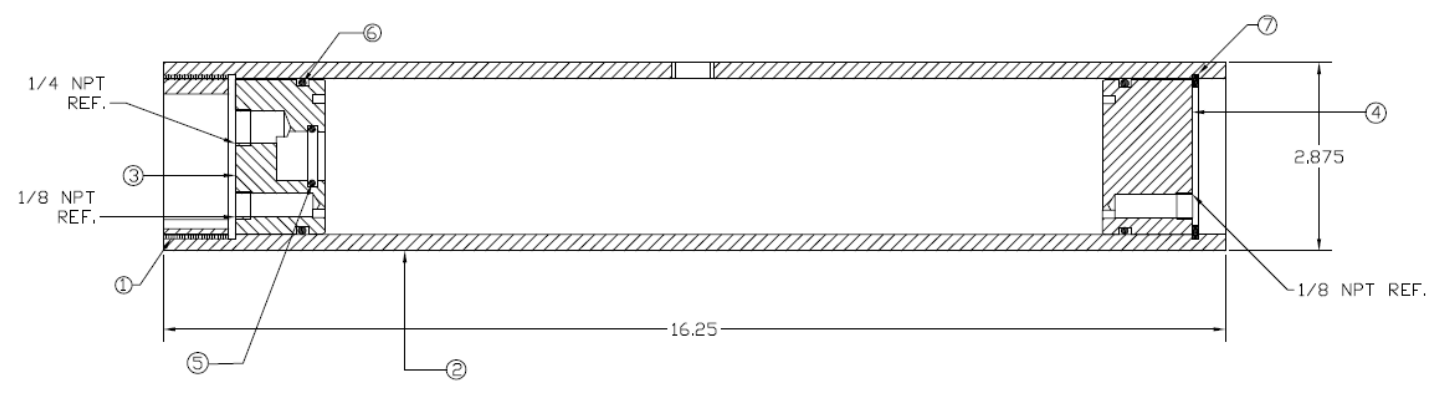

Figure 17. Hollow fiber module high pressure shell

Solvent compatibility of the PEEK cartridge was evaluated using commercial solvents, such as Morphysorb ${ }^{\circledR}$ and Selexol ${ }^{\circledR}$. Selexol ${ }^{\circledR}$ was compatible with all cartridge components. However, it was found the Morphysorb® solvent damaged several non-membrane cartridge components. It was also found that the O-rings were incompatible with this solvent. The O-ring design has been changed to Kelrez ${ }^{\mathrm{TM}}$ that has adequate solvent compatibility. The stainless steel spacer ring system was designed with insufficient tolerances that caused one of the epoxy tubesheets to crack. This has been corrected and design changes have been employed for future module construction.

\section{Subtask 2.3. $\mathrm{CO}_{2}$ capture performance demonstration}

Description of Work: In this subtask, the $\mathrm{CO}_{2}$ capture from simulated syngas by the membrane contactor (module size circa $10 \mathrm{ft}^{2}$ ) was measured. Physical solvents such as Selexol® and GTI's patented Morphysorb ${ }^{\circledR}$ were utilized initially as the absorbent system. The performance was measured at isothermal conditions (initially, $45^{\circ} \mathrm{C}$ for sorption). The gas flow was measured utilizing mass flow meters. The performance was assessed by measuring gas component concentrations $\left(\mathrm{CO}_{2}, \mathrm{H}_{2} \mathrm{~S}, \mathrm{He}, \mathrm{N}_{2}\right.$, and water vapor) in the feed, the retentate and the desorbed gas 
utilizing a gas chromatograph.

Helium was used in place of hydrogen due to safety concerns.

Project Activities/Products: Membrane modules with an active surface area of about $10 \mathrm{ft}^{2}$ were used in tests designed to measure the mass transfer coefficient as a function of gas flow rate, solvent flow rate, and total pressure. Design of experiments was used to construct the test matrix. Since there are only three variables, a full factorial design was used with high and low levels for each variable.

Table 5. Design of experiment test matrix

\begin{tabular}{|c|c|c|c|c|}
\hline STD & Run & $\begin{array}{c}\text { Gas Flow } \\
\text { Rate, } \\
\text { SLPM }\end{array}$ & $\begin{array}{c}\text { Solvent } \\
\text { Rate, } \\
\text { L/min }\end{array}$ & Pressure \\
\hline 6 & 1 & - & + & + \\
\hline 2 & 2 & - & - & + \\
\hline 8 & 3 & + & + & + \\
\hline 1 & 4 & - & - & - \\
\hline 7 & 5 & + & + & - \\
\hline 3 & 6 & + & - & - \\
\hline 5 & 7 & - & + & - \\
\hline 4 & 8 & + & - & + \\
\hline
\end{tabular}

Initial variable ranges used in the tests are: gas flow rate $=6$ and $12 \mathrm{~L} / \mathrm{min}$, solvent flow rate $=0.6$ and $1.2 \mathrm{~L} / \mathrm{min}$, and pressure $=400$ and $500 \mathrm{psig}$, respectively. The initial $\mathrm{CO}_{2}$ removal test results with Selexol® solvent are summarized below. These tests used a mixture of $\mathrm{N}_{2}$ and $\mathrm{CO}_{2}$ as the feed gas stream.

Table 6. $\mathrm{CO}_{2}$ Removal test results using Selexol ${ }^{\mathrm{TM}}$ (Module 2PG70)

\begin{tabular}{|c|c|c|c|c|c|c|c|c|c|}
\hline $\begin{array}{l}\mathbf{N}_{2} \\
\text { Flow } \\
\text { Rate, } \\
\text { SLPM }\end{array}$ & $\begin{array}{l}\mathrm{CO}_{2} \\
\text { Flow } \\
\text { Rate, } \\
\text { SLPM }\end{array}$ & $\begin{array}{l}\text { Total } \\
\text { Flow } \\
\text { SLPM } \\
\end{array}$ & $\begin{array}{l}\text { Solvent } \\
\text { Rate, } \\
\text { L/min }\end{array}$ & $\begin{array}{l}\text { Solvent } \\
\text { T, F }\end{array}$ & $\begin{array}{l}\text { Gas } \\
\text { P, } \\
\text { psi }\end{array}$ & $\begin{array}{l}\mathrm{In} \\
\mathrm{CO}_{2} \\
\mathrm{~mol} \%\end{array}$ & $\begin{array}{l}\text { Out } \\
\mathrm{CO}_{2} \\
\mathrm{~mol} \% \\
\end{array}$ & $\begin{array}{l}\% \mathrm{CO}_{2} \\
\text { Removal }\end{array}$ & $\begin{array}{l}\mathrm{KgAv}, \\
\mathrm{kmol} /\left(\mathrm{m}^{3} \cdot \mathrm{hr} . \mathrm{kPa}\right)\end{array}$ \\
\hline 3.55 & 2.51 & 6.06 & 1.18 & 105 & 518 & $40.3 \%$ & $19.1 \%$ & $52.5 \%$ & 0.00277 \\
\hline 3.54 & 2.50 & 6.04 & 0.60 & 105 & 506 & $38.9 \%$ & $17.3 \%$ & $55.7 \%$ & 0.00292 \\
\hline 7.12 & 5.00 & 12.12 & 1.20 & 105 & 512 & $40.7 \%$ & $20.1 \%$ & $50.6 \%$ & 0.00544 \\
\hline 3.54 & 2.50 & 6.04 & 0.60 & 105 & 407 & $37.7 \%$ & $18.4 \%$ & $51.0 \%$ & 0.00319 \\
\hline 7.08 & 5.00 & 12.08 & 1.18 & 105 & 409 & $39.7 \%$ & $19.2 \%$ & $51.7 \%$ & 0.00674 \\
\hline 7.07 & 5.00 & 12.07 & 0.55 & 105 & 400 & $37.8 \%$ & $21.2 \%$ & $43.9 \%$ & 0.00551 \\
\hline 3.52 & 2.51 & 6.03 & 1.18 & 105 & 401 & $39.7 \%$ & $20.1 \%$ & $49.2 \%$ & 0.00324 \\
\hline 7.12 & 5.00 & 12.12 & 0.59 & 105 & 515 & $39.0 \%$ & $21.0 \%$ & $46.1 \%$ & 0.00471 \\
\hline 7.10 & 5.00 & 12.10 & 0.60 & 105 & 518 & $41.0 \%$ & $26.1 \%$ & $36.2 \%$ & 0.00381 \\
\hline 9.70 & 2.40 & 12.10 & 0.60 & 105 & 518 & $20.6 \%$ & $12.3 \%$ & $40.2 \%$ & 0.00371 \\
\hline 3.50 & 2.50 & 6.00 & 0.60 & 105 & 518 & $39.7 \%$ & $18.2 \%$ & $54.1 \%$ & 0.00278 \\
\hline 4.80 & 1.20 & 6.00 & 0.60 & 105 & 518 & $19.0 \%$ & $9.2 \%$ & $51.4 \%$ & 0.00239 \\
\hline 1.80 & 1.20 & 3.00 & 0.60 & 105 & 518 & $35.2 \%$ & $15.7 \%$ & $55.4 \%$ & 0.00133 \\
\hline 2.40 & 0.60 & 3.00 & 0.60 & 105 & 518 & $17.8 \%$ & $7.6 \%$ & $57.1 \%$ & 0.00134 \\
\hline 19.59 & 5.00 & 24.59 & 0.60 & 105 & 511 & $23.9 \%$ & $13.9 \%$ & $42.1 \%$ & 0.00853 \\
\hline
\end{tabular}

These results indicate the $\% \mathrm{CO}_{2}$ removal did not change with changes in any of the three variables while the overall mass transfer coefficient increased with increasing total gas flow rate. 
These results are unexpected and show that the membrane module can handle much more gas than we initially thought. More tests are required to find out the maximum gas flow rate and the mass transfer coefficient. Since we are already at the solvent flow limit of the test apparatus, a smaller module with less membrane area may be needed to measure at the maximum gas flow rate.

The PEEK membrane contactor was also tested using Morphysorb® solvent system for $\mathrm{CO}_{2}$ capture under simulated syngas conditions. We encountered difficulties using PEEK contactor in combination with Morphysorb ${ }^{\circledR}$ solvent system. The problems were traced to incompatibility of the O-ring seals with the Morphysorb ${ }^{\circledR}$ solvent system and cartridge deformation due to a mild swelling of PEEK hollow fibers in an aggressive aldehyde component of solvent system. The problems encountered were rectified by incorporating a specialty Kelrez ${ }^{\circledR}$ O-ring system and by modifying the PEEK hollow fiber spinning protocol to modify porous hollow fiber morphology to reduce solvent swelling.

\section{Task 3. Membrane Process Design and Economic Evaluation}

Description of Work: Preliminary syngas separation process design based on the novel membrane contactor will be carried out and the process economics evaluated. Separation process modeling will utilize a first principle model developed by GTI for the membrane contactor system. Process economics will utilize The DOE Cost and Performance Baseline for Fossil Energy Plants Case Number 2 found in Reference DOE-NETL-2007/1281 by removing the costs for the $\mathrm{CO}_{2}$ control system in that analysis and replacing it with the costs for GTI's new concept. The analyses will provide for initial design of process conditions that in turn will provide feedback for the design of flow dynamics in the hollow fiber module. The initial syngas treatment economics will be performed by GTI.

Project Activities/Products: Membrane contactor process is modeled as 1-D reaction-diffusion problem where the solvent flows in the shell side and gas flows in the tube side ${ }^{8}$. The assumptions used to develop the model are: 1) the gas phase is perfectly mixed laterally and,2) gas phase is in axial plug flow 3) isothermal conditions, 4) constant physical properties. The model is designed to handle both counter- or co-current flow configurations.

Gas phase balance: Using the plug-flow assumption, the mass balance equation for the gas phase is given by

$$
\left.\left(1-\varepsilon_{b}\right) U_{g} C_{i, g} A_{b}\right|_{z}-\left.\left(1-\varepsilon_{b}\right) U_{g} C_{i, g} A_{b}\right|_{z+\Delta z}-N_{i} n_{f} 2 \pi R_{i} \Delta z=0
$$

where, $\mathrm{U}_{\mathrm{g}}$ is the gas velocity, $\mathrm{C}_{\mathrm{i}, \mathrm{g}}$ is the species concentration, $\mathrm{A}_{\mathrm{b}}$ is the cross-sectional area of the bundle, $\mathrm{N}_{\mathrm{i}}$ is the flux from the gas side to the liquid side through the membranes, $\mathrm{n}_{\mathrm{f}}$ is the total number of fibers, $\varepsilon_{b}$ is the bundle porosity, and $R_{i}$ is the inner radius of the fiber.

The flux $\mathrm{N}_{\mathrm{i}}$ in terms of the overall mass transfer coefficient is given by

$$
N_{i}=K_{o v}\left(C_{i, g}-H_{i} C_{i, l}\right)
$$


where, $\mathrm{K}_{\mathrm{ov}}$ is the overall mass transfer coefficient, $\mathrm{H}_{\mathrm{i}}$ is the dimensionless Henry's law constant for the gas species, and $\mathrm{C}_{\mathrm{i}, 1}$ is the liquid phase concentration. Substituting the above equation in the overall mass balance equation for the gas phase and rearranging, we have

$$
\frac{d C_{i, g}}{d z}+\frac{L_{b}}{L_{f}} \frac{K_{o v} a_{b}}{\varepsilon_{g A} U_{g}}\left(C_{i, g}-H_{i} C_{i, i}\right)=0
$$

Here, $\mathrm{L}_{\mathrm{b}}$ is the length of the bundle, $\mathrm{L}_{\mathrm{f}}$ is the length of the fiber and $\varepsilon_{\mathrm{gA}}$ is the flow cross section available for gas flow $\left(\varepsilon_{\mathrm{gA}}=1-\varepsilon_{\mathrm{b}}\right)$, and $\mathrm{a}_{\mathrm{b}}$ is the specific surface area of the fibers based on the bundle volume.

Liquid phase balance: The liquid phase mass balance under the assumption of plug flow is formulated similarly and can be given by

$$
\left.\varepsilon_{l A} U_{l} C_{i, l} A_{m}\right|_{g}-\left.\varepsilon_{l A} U_{l} C_{i, l} A_{m}\right|_{g+\Delta g}+N_{i} n_{f} 2 \pi R_{i} \Delta z-r_{i} \varepsilon_{l A} A_{m} \Delta z=0
$$

Here, $\mathrm{U}_{1}$ is the liquid velocity, $\mathrm{C}_{\mathrm{i}, 1}$ is the species concentration, $\mathrm{A}_{\mathrm{m}}$ is the cross-sectional area of the module, $\varepsilon_{\mathrm{IA}}$ is the flow cross section available for liquid flow, and $\mathrm{r}_{\mathrm{i}}$ is the rate of reaction of the absorbing species. Substituting the flux equation $\left(\mathrm{N}_{\mathrm{i}}\right)$ as before and rearranging, the resulting liquid phase mass balance equation can be written as

$$
\frac{d C_{i, l}}{d z}+\left[\frac{L_{b}}{L_{f}} \frac{K_{o \nu} a_{m}}{U_{l} \varepsilon_{l A}} H_{i}+\frac{k_{i}}{U_{l}}\right] C_{i, L}-\frac{L_{b}}{L_{f}} \frac{K_{o v} a_{m a}}{U_{l} \varepsilon_{l A}} C_{i, g}=0
$$

where, $k_{i}$ is the pseudo-first order reaction rate constant and $a_{m}$ is the specific surface area of the fibers based on the membrane module volume.

Solution procedure: The coupled first order differential equations are first transformed to the Laplace domain and then solved analytically. The overall mass transfer coefficient can be estimated using series resistance approach, where the mass transfer process consists of three consecutive steps. (1) diffusion of $\mathrm{CO} 2$ from the bulk gas to the membrane-gas interface (2) diffusion through membrane pores to the membrane-liquid interface (3) absorption followed by chemical reaction in the solvent phase (reaction-diffusion). It may be noted that the transfer coefficient may be input to the model as well.

Process Economics modeling was accomplished by substituting the absorber with the membrane contactor. The cost of membrane is set at $\$ 100 / \mathrm{m}^{2}$, which is the current small-scale cost of the membrane. This cost is expected to drop below $\$ 50 / \mathrm{m}^{2}$ for large-scale production and drop further with maturity of the production process. The results show that the capital cost can be decreased by more than $7 \%$ from the baseline Case 2. This is a substantial decrease since the total capital cost for Case 2 is about $\$ 1.4$ billion dollars. 
The cost of electricity as indicated by the levelized cost of electricity (LCOE) provides a common way to compare the cost of energy across technologies because it takes into account the installed system price and associated costs such as financing, land, insurance, transmission, operation and maintenance, and depreciation, among other expenses. Carbon emission costs can also be taken into account. The LCOE is a true apples-to-apples comparison of the cost of electricity.

Table 7. LCOE of base case IGCC plants with and without $\mathrm{CO}_{2}$ capture compared with membrane contactor process for $\mathrm{CO}_{2}$ capture IGCC plant in $2006 \$$.

\begin{tabular}{|c|c|c|c|c|}
\hline \multirow[b]{2}{*}{ Cost } & \multicolumn{3}{|c|}{ LCOE (\$/MW) } & \multirow[b]{2}{*}{$\begin{array}{l}\text { \% Change } \\
\text { from Case } 2\end{array}$} \\
\hline & Case 1 & Case 2 & $\begin{array}{l}\text { Membrane } \\
\text { Contactor } \\
\left(\$ 100 / \mathbf{m}^{2}\right)\end{array}$ & \\
\hline Capital & $\$ 45.28$ & $\$ 59.65$ & $\$ 55.27$ & $-7.3 \%$ \\
\hline Fixed & $\$ 6.05$ & $\$ 7.50$ & $\$ 7.50$ & $0 \%$ \\
\hline Variable & $\$ 7.51$ & $\$ 9.35$ & $\$ 9.35$ & $0 \%$ \\
\hline Coal & $\$ 19.36$ & $\$ 22.78$ & $\$ 22.78$ & $0 \%$ \\
\hline $\mathrm{CO}_{2}$ & $\$ 0$ & $\$ 3.66$ & $\$ 3.66$ & $0 \%$ \\
\hline Total & $\$ 78.20$ & $\$ 102.94$ & $\$ 98.56$ & $-4.3 \%$ \\
\hline
\end{tabular}

The data in Table 7 above show that the LCOE increased by $26 \%$ as compared with the base DOE Case 1 with no capture, and decreased by $4.3 \%$ from the state of art technology DOE Case 2.

The sensitivity of LCOE with respective to membrane cost is also estimated and the results show in the Figure 18. 


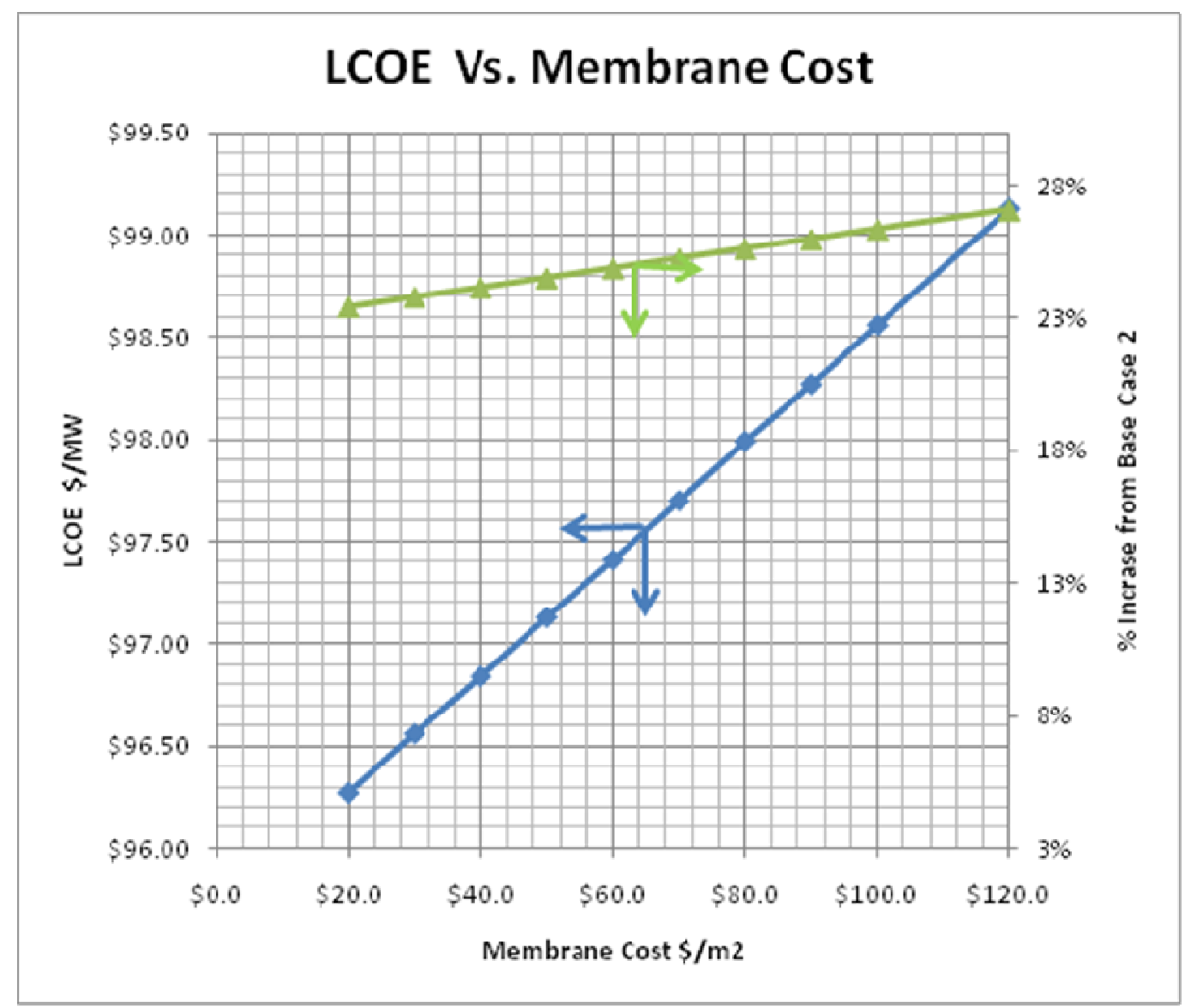

Figure 18. Sensitivity analysis of LCOE as a function of membrane cost.

Refined economics results are presented in Task 9.

\section{Task 5. Membrane Contactor Manufacturing Process Scale Up}

Membrane contactor module scales up studies were performed to determine the process variables for fabrication of large size modules suitable for pilot scale demonstration of the proposed technology. Process for larger size module fabrication for full-scale application was also be studied to determine the upper limit of the manufacturing process. It was expected that a large scale contractor will required to conduct pilot tests and test plan will be required for conducting these tests.

Project Activities/Products: The design of commercial-size membrane contactor module was completed. The contactor cartridge size is 8 -inch diameter by 5-feet long. The contactor cartridge will be housed in a 10-inch flanged pressure shell designed for syngas high pressure operation (1000 psig feed pressure). The contactor will contain about $1000 \mathrm{ft}^{2}$ of hollow fiber membrane area.

The flow configurations (syngas and physical solvent flow paths) in the module are shown in Figure 19. 


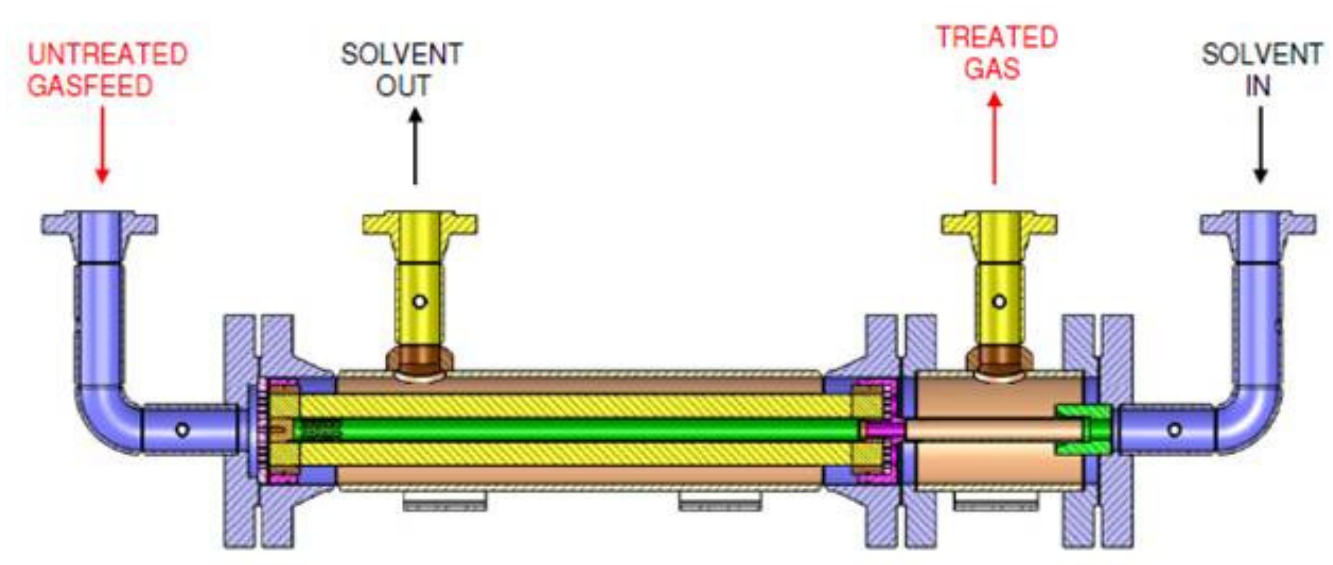

Figure 19. Contactor flow model

The manufacturing scale up further included development of manufacturing procedures and equipment upgrades required to enable construction of super-hydrophobic PEEK hollow fiber membranes and contactor membrane cartridges.

Manufacturing process for preparation of porous PEEK hollow fibers used for the preparation of super-hydrophobic PEEK hollow membranes fibers was scaled up successfully. The porous PEEK hollow fiber substrate was prepared from a blend of two plastic materials poly(ether ether ketone), PEEK, and polyether imide, Ultem ${ }^{\mathrm{TM}}$, by a high temperature melt extrusion process as discussed above. PEEK hollow fiber membranes with target porosity (surface pore size below $5 \mathrm{~nm}$ and balk pore size of $15 \mathrm{~nm}$ ) have been prepared on commercial equipment.

Initial steps to scale up the manufacturing process for preparation of super-hydrophobic PEEK hollow fiber membranes were undertaken to prepare commercial size membrane cartridges with $1000 \mathrm{ft}^{2}$ membrane area. The equipment for super-hydrophobic PEEK hollow fiber membrane preparation and quality testing is shown in Figure 20.
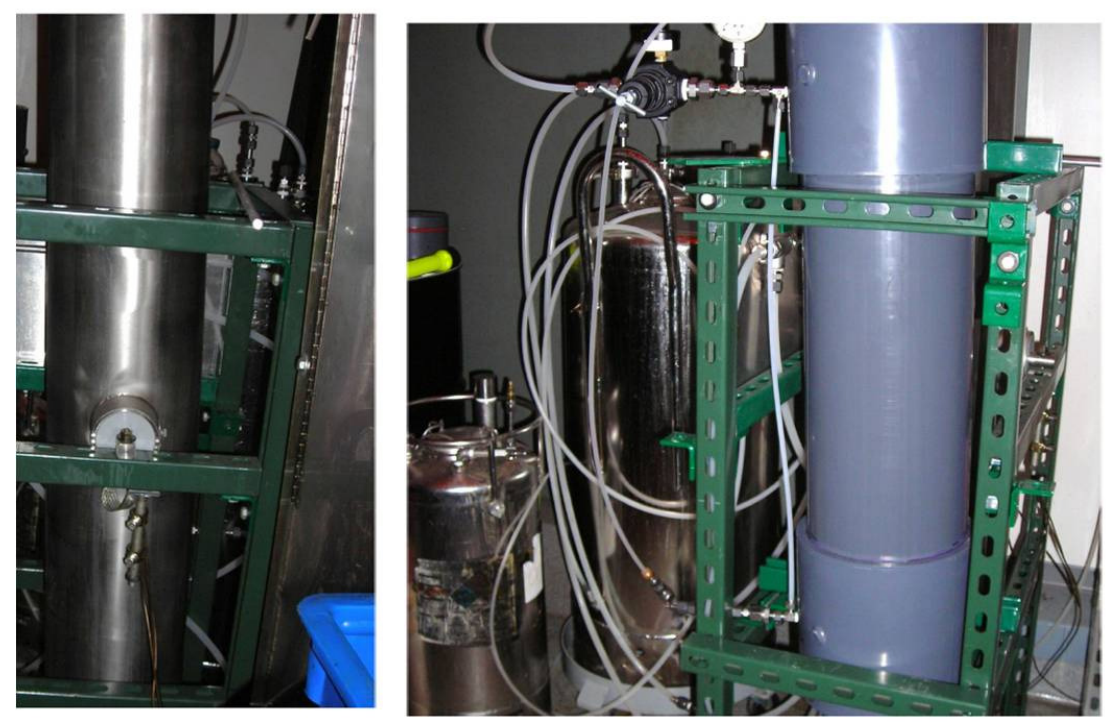

DE-FE-0000646 Final Technical Report 


\section{Figure 20. Equipment for 8-inch cartridge manufacture and QC testing}

As discussed in privius sections PoroGen manufactures hollow fiber cartridges by constructing cartridges using computer controlled helical winding. The process generates a structured packing with optimal flow dynamics. The structured configuration minimizes concentration polarization on liquid side and eliminates bypassing and channeling. The winding of large size cartridges was successully demonstrated.

The commercial scale up further included the final step in contactor manufacture cartridge potting to form terminal tubesheets. The tubesheets separate the liquid side of the contactor from the gas side and provide for fluid tight seal. The cartridge is further sealed to pressure shell with o-rings. The 8-inch cartridge with formed terminal tubesheet is shown in Figure 21.

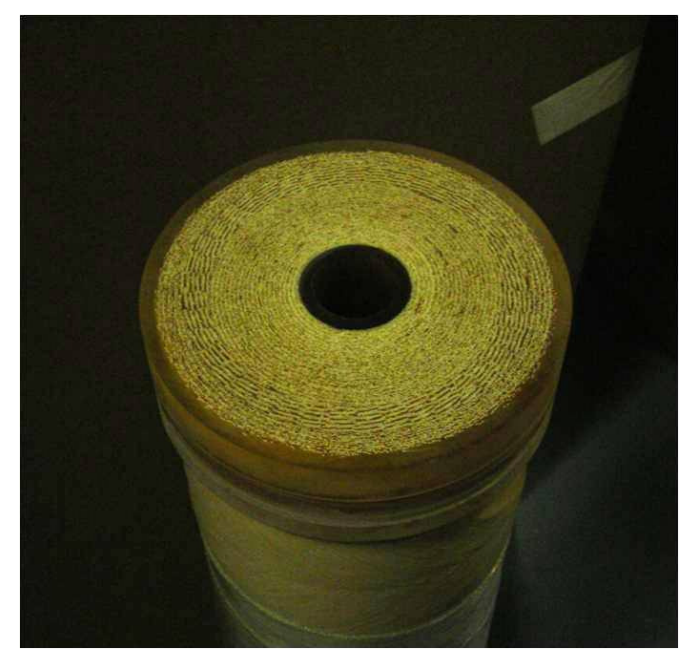

Figure 21. Commercial 8-inch diamter hollow fiber cartridge (terminal tubesheet end)

\section{Task 6. Membrane Contactor Stability and Life Testing}

Membrane contactor modules must be tested to determine contactor stability vs. process variables and contactor life as function of contaminant levels. Factors that influence membrane contactor life are wetting of the membrane by the solvent, pore plugging, and membrane material degradation. Membrane wetting tests must be performed with select solvents as function of time and differential pressure. Mass transfer coefficient and solvent intrusion to the gas side was used to determine the extent of membrane wetting. Membrane pore plugging must be determined as a function of amount of particles in the gas at a pre-determined particle size representative of the typical syngas after clean up steps. Membrane material compatibility with selected solvents must be tested using both physical properties measurement of PEEK fiber exposed to the solvent for given periods of time and by conducting mass transfer tests. The contractor prepared using the procedure developed during this program was evaluated following an evaluation test plan. The test plan was provided to DOE for review, prior to conducting tests.

Project Activities/Products: We have identified critical components to undergo stability and life testing based on the module design developed in Task 5. The test program entailed exposure of major critical contactor components such as PEEK membrane, epoxy tubesheet, and O-rings to

DE-FE-0000646 Final Technical Report 
solvent system at process temperature. Material stability towards solvents such as water and physical solvents was evaluated. The membrane stability was evaluated by comparing initial gas transport characteristics to gas transport characteristics after predetermined exposure. The epoxy materials characteristics (tensile strength and modulus) prior and after exposure are compared as well. The effect of solvent on O-rings is examined visually; the extent of swelling if any is measured as well as the ability to provide fluid tight seal after exposure.

Several bench scale test modules were constructed by PoroGen and supplied to GTI. The modules were also tested initially in the bench scale lab test to establish start up and shut down protocols in preparation for test in gasifier facility.

Two modules failed during initial startup due to development of high, unplanned differential pressure - several hundred psig of differential pressure developed from the gas side to the liquid side. The high differential pressure caused catastrophic tubesheet failure (see the picture below). A section of the tubesheet broke off at the high differential pressure.

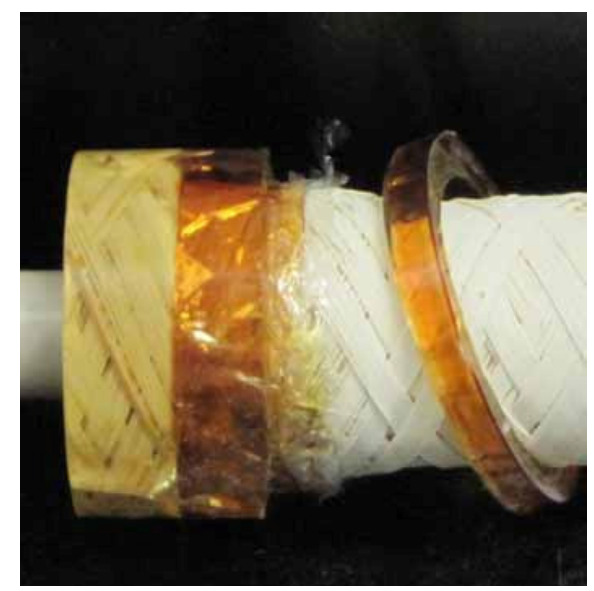

Figure 22. Broken tubesheet due to high differential pressure.

A third module failed as well. However, the third module did not fail as a result of tubesheet failure but due to hollow fiber wet out under the high reverse differential pressure conditions. The higher differential pressure expanded the fiber and increased the pore size of the fiber irreversibly. Larger pores are much easier to wet than smaller pores because of surface tension effects. The start up and shut down procedures have been modified as well as the overall system design to prevent future failures upon start up. The system was modified to provide for gas liquid side pressure differential control. The liquid backpressure is controlled by a retentate gas and the differential pressure is maintained at a pre-determined level at all times.

The most critical component of the membrane contactor is the PEEK hollow fibers contained in the membrane module. Prolonged exposure of PEEK membrane to simple physical solvents such as water or methanol showed no effect on membrane performance. To study the effect of solvents on membrane contactor stability, we have adopted an aggressive solvent activated methyldiethanolamine (aMDEA). The $\mathrm{CO}_{2}$ capture process was continuously run through module 2PG283 with activated methyldiethanolamine (aMDEA) solvent for several days. aMDEA is a much more aggressive solvent than physical solvents and was used as an accelerated test. The test module had an intrinsic $\mathrm{CO}_{2}$ permeance of $586 \pm 13$ GPU initially as

DE-FE-0000646 Final Technical Report 
shown in Table 8. The membrane intrinsic permeances for $\mathrm{CO}_{2}$ after testing is alsolisted in Table 8 . The final gas permeance values were identical to the initial values.

Table 8. The membrane intrinsic permeances for $\mathrm{CO}_{2}$ and $\mathrm{N}_{2}$ through module 2PG283

\begin{tabular}{|l|l|c|}
\hline \multirow{2}{*}{ Condition } & \multirow{2}{*}{ Tested date } & Intrinsic permeance, GPU \\
\cline { 3 - 3 } & & $\mathbf{C O}_{2}$ \\
\hline Initial membrane module & $6 / 22 / 2011^{*}$ & $586 \pm 13$ \\
\hline $\begin{array}{l}\text { Module after being used for } \mathrm{CO}_{2} \text { capture using } \\
\text { aMDEA. Then, it was wished with D.I. water and } \\
\text { dried. }\end{array}$ & $\begin{array}{c}11 / 11 / 2011 \\
* *\end{array}$ & 595 \\
\hline $\begin{array}{l}\text { Module after being used for } \mathrm{CO}_{2} \text { capture for 124 } \\
\text { hours, wetted with aMDEA solvent for 55 days. } \\
\text { Then, it was wished with D.I. water and dried. }\end{array}$ & $1 / 17 / 2012^{*}$ & $586 \pm 14$ \\
\hline
\end{tabular}

*: Intrinsic permeances for $\mathrm{CO}_{2}$ was measured at three different trans-membrane pressure drops. The average permeance was given in the table. All the \pm values are standard deviations.

**: Intrinsic permeances of $\mathrm{CO}_{2}$ was measured at one trans-membrane pressure drop.

In the stability experiment, the solvent was recirculated to the feed drum without a regeneration step, causing the $\mathrm{CO}_{2}$ loading of the solvent to increase with time during the run. Operating conditions are listed in Table 9.

Table 9. Long-term stability operating conditions

\begin{tabular}{|l|l|}
\hline Parameter & Condition \\
\hline Gas inlet temperature & 130 to $137^{\circ} \mathrm{F}$ \\
\hline Simulated gas $\mathrm{CO}_{2}$ inlet concentration & $13 \mathrm{~mol} \%$ (balance $\left.\mathrm{N}_{2}\right)$ \\
\hline Moisture & Saturation \\
\hline Membrane contactor surface area & $0.13 \mathrm{~m}^{2}$ \\
\hline Gas flow rate & $1 \mathrm{SLPM}$ \\
\hline Liquid inlet temperature & 107 to $116^{\circ} \mathrm{F}$ \\
\hline Liquid flow rate & $0.42 \mathrm{~L} / \mathrm{min}$ \\
\hline Inlet liquid pressure & $<2 \mathrm{psig}$ \\
\hline
\end{tabular}

The gas side pressure drop was stable throughout the experiment confirming that the module fiber bores were not plugged by liquid water, see Figure 23. Figure 24 shows that the liquid side pressure drop also remained less than 2 psi during the test period. 


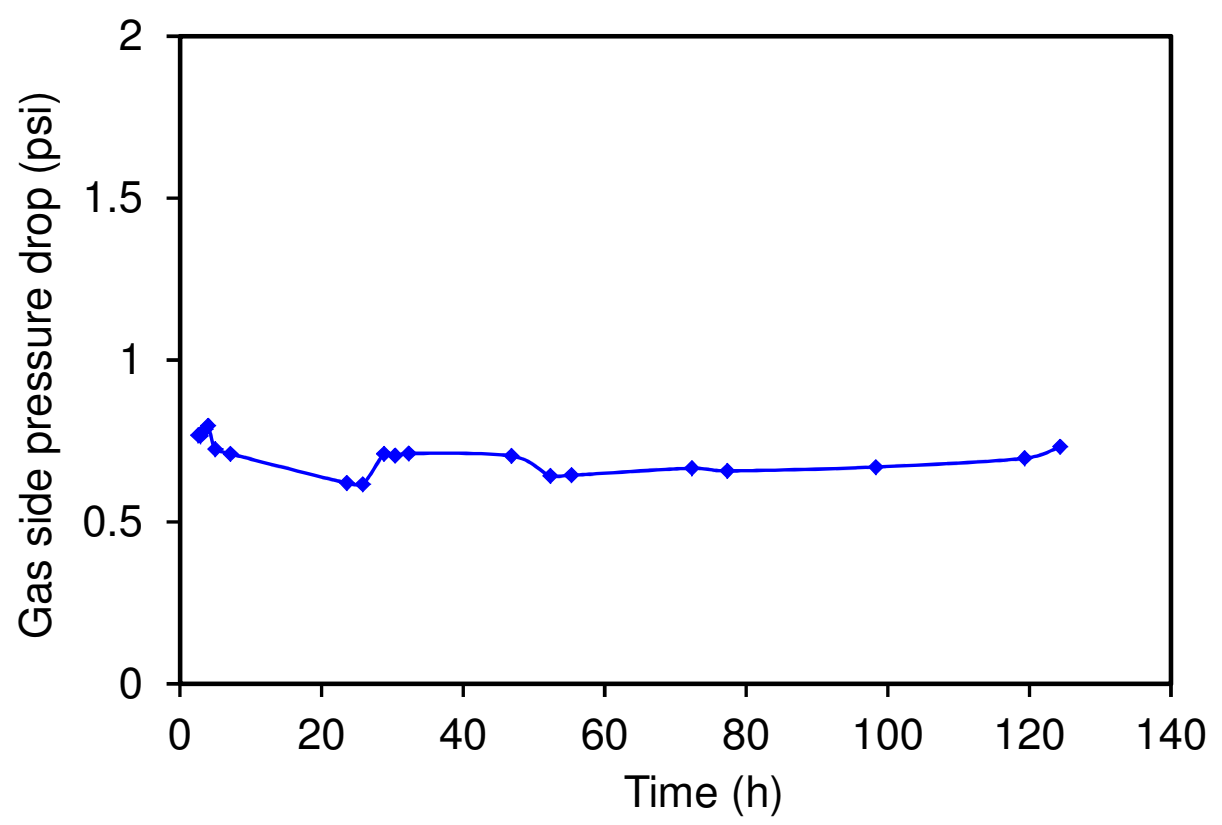

Figure 23. Gas side pressure drop as a function of operating time for module 2PG283.

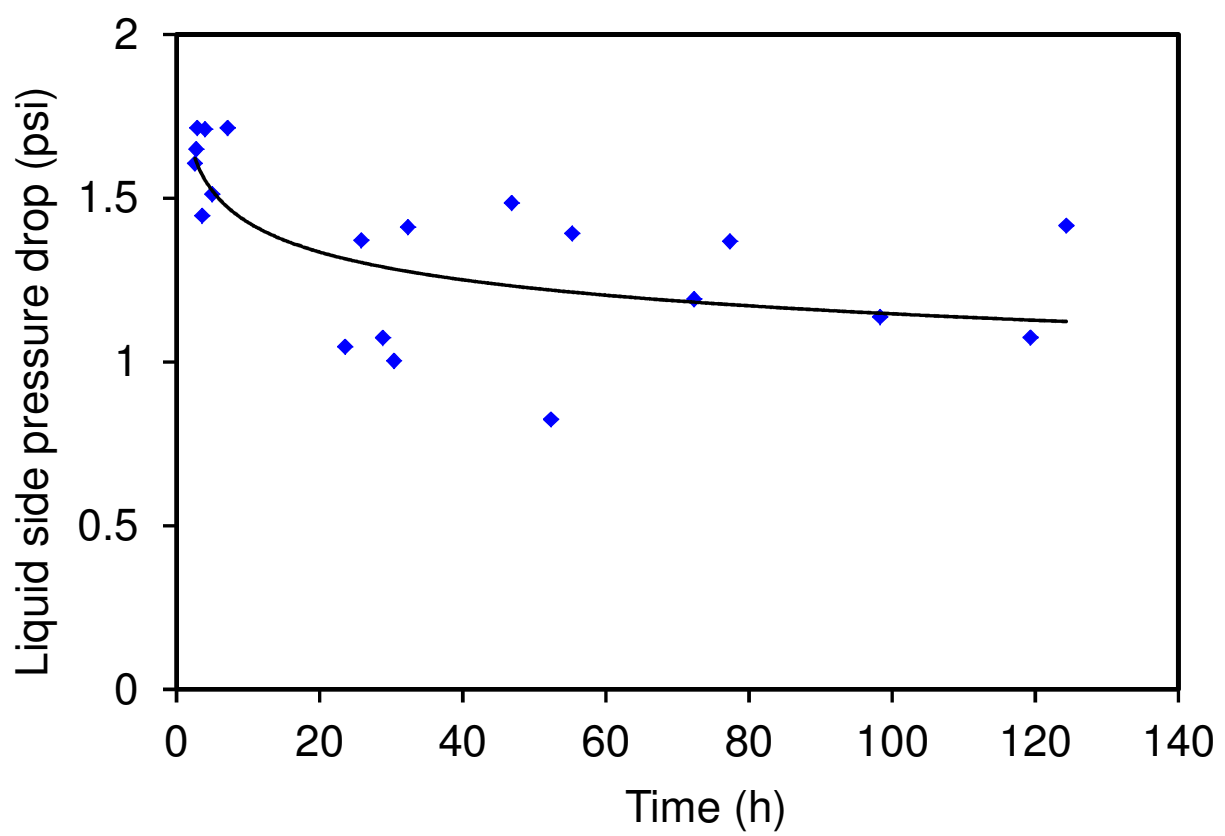

Figure 24. Liquid side pressure drop as a function of operating time for module 2PG283.

The module was re-tested for single-gas permeation. The measured intrinsic permeances for $\mathrm{CO}_{2}$ is shown in Table 8. The values obtained were identical to the initial ones. This is a good indication that the mechanical properties and permeation properties of the module did not changed after 124 hours of $\mathrm{CO}_{2}$ capture and after being in contact with solvent for 55 days. 


\section{Task7. Bench Scale Testing of Membrane Contactors}

In this task, membrane contactor modules were tested to optimize the process in terms of solvent flow, pressure drop, temperature, $\mathrm{CO}_{2}$ loading, regeneration methods. A fractional design of experiment matrix was used to screen the variables. These tests establish the correlation between the variables and the most important factors affecting membrane contactor performance. A reduced variable matrix can then be established for further optimization with full factorial design of experiment runs. The contractor of relevant size was prepared and a test plan formulated for conducting these bench-scale tests.

Project Activities/Products: Several membrane contactor modules with varying properties and structural components were tested in GTI laboratory using the design of experimental test matrix shown in Table 5. Test results are summarized below. 
Table 10. Membrane contactor $\mathrm{CO}_{2}$ removal tests using water as solvent (Module 2PG243)

\begin{tabular}{|c|c|c|c|c|c|c|c|c|c|c|c|c|c|c|}
\hline $\begin{array}{l}\mathrm{CO}_{2} \\
\text { Flow, } \\
\text { SLPM }\end{array}$ & $\begin{array}{c}\mathrm{N}_{2} \\
\text { Flow } \\
\text { SCFH }\end{array}$ & $\begin{array}{l}\text { Liquid } \\
\text { Flow, } \\
\text { L/min }\end{array}$ & $\begin{array}{c}\text { Gas } \\
\text { Inlet, } \\
{ }^{\circ} \mathrm{F}\end{array}$ & $\begin{array}{c}\text { Gas } \\
\text { Outlet } \\
,{ }^{\circ} \mathrm{F}\end{array}$ & $\begin{array}{l}\text { Liquid } \\
\text { Inlet, } \\
{ }^{\circ} \mathrm{F}\end{array}$ & $\begin{array}{c}\text { Liquid } \\
\text { Outlet, } \\
{ }^{\circ} \mathrm{F}\end{array}$ & $\begin{array}{c}\text { Gas } \\
\text { Inlet, } \\
\text { psig }\end{array}$ & $\begin{array}{c}\text { Gas } \\
\text { Outlet, } \\
\text { psig }\end{array}$ & $\begin{array}{c}\text { Liquid } \\
\text { Inlet, } \\
\text { psig }\end{array}$ & $\begin{array}{c}\text { Inlet } \\
\mathrm{CO}_{2}, \\
\%\end{array}$ & $\begin{array}{c}\text { Outlet } \\
\mathrm{CO}_{2} \text {, } \\
\%\end{array}$ & $\begin{array}{l}\text { Total } \\
\text { Inlet } \\
\text { Gas, } \\
\text { SCFH }\end{array}$ & $\begin{array}{c}\text { Total } \\
\text { Outlet } \\
\text { Gas, } \\
\text { SCFH }\end{array}$ & $\begin{array}{c}\% \\
\text { Removal }\end{array}$ \\
\hline 4.8 & 15.9 & 0.68 & 79.0 & 76.1 & 62.8 & 66.7 & 501 & 493 & 513 & 39.23 & 0.96 & 26.1 & 16.0 & 98.5 \\
\hline 11.5 & 34.4 & 0.83 & 77.2 & 74.4 & 66.3 & 70.3 & 502 & 494 & 511 & 41.4 & 18.3 & 58.7 & 38.0 & 71.4 \\
\hline 4.98 & 15.7 & 0.38 & 78.2 & 76.7 & 76.1 & 78.1 & 101 & 99.1 & 106 & 38 & 32.5 & 26.3 & 21.1 & 31.2 \\
\hline 4.96 & 15.1 & 0.88 & 78.3 & 76.7 & 75.8 & 77.6 & 101 & 98.7 & 109 & 39.4 & 26.5 & 25.6 & 18.9 & 50.3 \\
\hline 6.44 & 17.6 & 1.68 & 79.3 & 77 & 72.4 & 75.5 & 498 & 491 & 510 & 38.9 & 0.5 & 31.2 & 21.5 & 99.1 \\
\hline 9.45 & 22.2 & 1.68 & 78.9 & 76.4 & 65.8 & 69.1 & 500 & 493 & 504 & 43.9 & 1.4 & 42.2 & 25.8 & 98.1 \\
\hline 9.45 & 22.2 & 1.45 & 78.3 & 75.5 & 63 & 66.1 & 500 & 493 & 505 & 43 & 2.2 & 42.2 & 26.8 & 96.7 \\
\hline 9.46 & 25.1 & 1.42 & 78 & 76.5 & 73.1 & 75.3 & 100 & 97.1 & 113 & 43.6 & 33.5 & 45.1 & 32.1 & 45.4 \\
\hline 19.2 & 46.16 & 1.42 & 76.5 & 74.8 & 74.7 & 76.6 & 101 & 98.7 & 110 & 38.5 & 33.2 & 86.8 & 80.2 & 20.3 \\
\hline 3.98 & 10.7 & 1.42 & 74.7 & 73.3 & 74.9 & 77 & 99.5 & 97 & 109 & 40 & 17.3 & 19.1 & 13.9 & 68.6 \\
\hline 3.48 & 9.60 & 1.42 & 71.5 & 70.8 & 74.8 & 77.3 & 101 & 98.7 & 107 & 40.5 & 16 & 17.0 & 11.8 & 72.5 \\
\hline 1.99 & 6.38 & 1.39 & 78.5 & 76.7 & 74.7 & 76.2 & 102 & 99.4 & 107 & 37.7 & 6.6 & 10.6 & 7.2 & 88.1 \\
\hline 9.6 & 30.11 & 1.22 & 76.2 & 71.5 & 57 & 60.2 & 103 & 100 & 110 & 38 & 26.5 & 50.4 & 44.3 & 9.6 \\
\hline 9.46 & 25.9 & 1.42 & 78 & 76.5 & 73.1 & 75.3 & 100 & 97.1 & 113 & 43.6 & 33.5 & 45.9 & 9.46 & 25.9 \\
\hline 9.61 & 23.53 & 1.30 & 75.3 & 73 & 55.1 & 59 & 499 & 492 & 508 & 40.3 & 11.5 & 43.9 & 29.3 & 80.9 \\
\hline 9.61 & 27.77 & 1.29 & 77.3 & 75.4 & 75 & 78 & 500 & 494 & 508 & 44.5 & 8.8 & 48.1 & 31.8 & 86.9 \\
\hline 18.7 & 58.52 & 1.22 & 76.3 & 67.9 & 55 & 58.4 & 103 & 100 & 106 & 38.3 & 33.1 & 98.1 & 92.8 & 18.3 \\
\hline 19.2 & 65.02 & 1.42 & 76.5 & 74.8 & 74.7 & 76.6 & 101 & 98.7 & 110 & 38.5 & 33.2 & 105.7 & 100.1 & 18.3 \\
\hline 18.6 & 66.50 & 1.30 & 75.7 & 71.4 & 62.4 & 67 & 499 & 492 & 511 & 37.5 & 23.2 & 105.9 & 90.9 & 46.9 \\
\hline 18.2 & 55.55 & 1.29 & 77.1 & 75 & 74.9 & 78.4 & 501 & 494 & 507 & 43 & 25.1 & 94.1 & 78.1 & 51.6 \\
\hline
\end{tabular}

The data shown above were obtained using water as a physical solvent and using a test matrix of changing inlet total gas flow, inlet total gas pressure and inlet liquid flow rates. The calculated mass transfer coefficients are shown below: 
Table 11. Mass transfer coefficients from test results in Table 10.

\begin{tabular}{|c|c|c|c|c|c|c|c|c|c|}
\hline $\begin{array}{c}\mathrm{mol} / \mathrm{min} \\
\mathrm{CO}_{2} \\
\text { Removed }\end{array}$ & $\begin{array}{c}\text { Inlet } \\
\mathrm{CO}_{2} \mathrm{P} \text {, } \\
\text { psi }\end{array}$ & $\begin{array}{c}\text { Outlet } \\
\mathrm{CO}_{2} \mathrm{P} \text {, } \\
\text { psi }\end{array}$ & $\begin{array}{c}\text { Mean } \mathrm{CO}_{2} \\
\text { P, psi }\end{array}$ & $\begin{array}{c}\mathrm{K}_{\mathrm{G}}, \\
\mathrm{mol} /\left(\mathrm{m}^{2} \cdot \mathrm{hr} . \mathrm{Kpa}\right)\end{array}$ & $\begin{array}{c}\mathrm{K}_{\mathrm{G}} \mathrm{a}, \\
\mathrm{mol} /\left(\mathrm{m}^{3} . \mathrm{hr} .\right. \\
\text { Кра) }\end{array}$ & $\begin{array}{c}\mathrm{K}_{\mathrm{G}} \\
\mathrm{cm} / \mathrm{s}\end{array}$ & $\begin{array}{r}K_{G} a, \\
1 / s\end{array}$ & $\begin{array}{c}\mathrm{CO}_{2} \text { Removal Rate } \\
\mathrm{kg} /\left(\mathrm{m}^{2} . \mathrm{hr}\right)\end{array}$ & $\begin{array}{c}\text { Total Gas } \\
\text { Treated, SCFH }\end{array}$ \\
\hline 0.2127 & 196.3 & 4.7 & 100.5 & 0.0197 & 28.3 & 0.0012 & 0.0179 & 0.60 & 26.1 \\
\hline 0.3654 & 207.6 & 90.5 & 149.0 & 0.0228 & 32.8 & 0.0014 & 0.0207 & 1.03 & 58.7 \\
\hline 0.0655 & 38.4 & 32.2 & 35.3 & 0.0172 & 24.8 & 0.0011 & 0.0157 & 0.18 & 26.3 \\
\hline 0.1069 & 39.8 & 26.2 & 33.0 & 0.0301 & 43.4 & 0.0019 & 0.0274 & 0.30 & 25.6 \\
\hline 0.2537 & 193.7 & 2.5 & 98.1 & 0.0240 & 34.6 & 0.0015 & 0.0218 & 0.71 & 31.2 \\
\hline 0.3827 & 219.5 & 6.9 & 113.2 & 0.0314 & 45.2 & 0.0020 & 0.0285 & 1.08 & 42.2 \\
\hline 0.3699 & 215.0 & 10.8 & 112.9 & 0.0304 & 43.8 & 0.0019 & 0.0276 & 1.04 & 42.2 \\
\hline 0.1881 & 43.6 & 32.5 & 38.1 & 0.0459 & 66.1 & 0.0029 & 0.0417 & 0.53 & 45.1 \\
\hline 0.1431 & 38.9 & 32.8 & 35.8 & 0.0371 & 53.5 & 0.0023 & 0.0337 & 0.40 & 86.8 \\
\hline 0.1105 & 39.8 & 16.8 & 28.3 & 0.0363 & 52.3 & 0.0023 & 0.0330 & 0.31 & 19.1 \\
\hline 0.1050 & 40.9 & 15.8 & 28.3 & 0.0344 & 49.6 & 0.0022 & 0.0313 & 0.30 & 17.0 \\
\hline 0.0741 & 38.5 & 6.6 & 22.5 & 0.0306 & 44.1 & 0.0019 & 0.0278 & 0.21 & 10.6 \\
\hline 0.1565 & 44.7 & 30.4 & 37.6 & 0.0625 & 115.0 & 0.0039 & 0.0725 & 0.71 & 50.4 \\
\hline 0.1305 & 50.0 & 37.5 & 43.7 & 0.0447 & 82.3 & 0.0028 & 0.0519 & 0.59 & 45.9 \\
\hline 0.3014 & 207.0 & 58.3 & 132.6 & 0.0341 & 62.7 & 0.0021 & 0.0396 & 1.37 & 43.9 \\
\hline 0.3921 & 229.0 & 44.8 & 136.9 & 0.0429 & 79.0 & 0.0027 & 0.0499 & 1.78 & 48.1 \\
\hline 0.1449 & 45.1 & 38.0 & 41.5 & 0.0523 & 96.3 & 0.0033 & 0.0608 & 0.66 & 98.1 \\
\hline 0.1571 & 44.5 & 37.6 & 41.1 & 0.0573 & 105.5 & 0.0036 & 0.0666 & 0.71 & 105.7 \\
\hline 0.3923 & 192.6 & 117.6 & 155.1 & 0.0379 & 69.8 & 0.0024 & 0.0440 & 1.78 & 105.9 \\
\hline 0.4395 & 221.7 & 127.7 & 174.7 & 0.0377 & 69.4 & 0.0024 & 0.0438 & 2.00 & 94.1 \\
\hline
\end{tabular}

The calculated mass transfer coefficients are below the intrinsic permeance of the bare membrane indicating liquid-side mass transfer resistance. Liquid mass transfer resistance is generally caused by concentration polarization due to inadequate liquid velocity, high solvent viscosity, and slow diffusion of the absorbing species. 


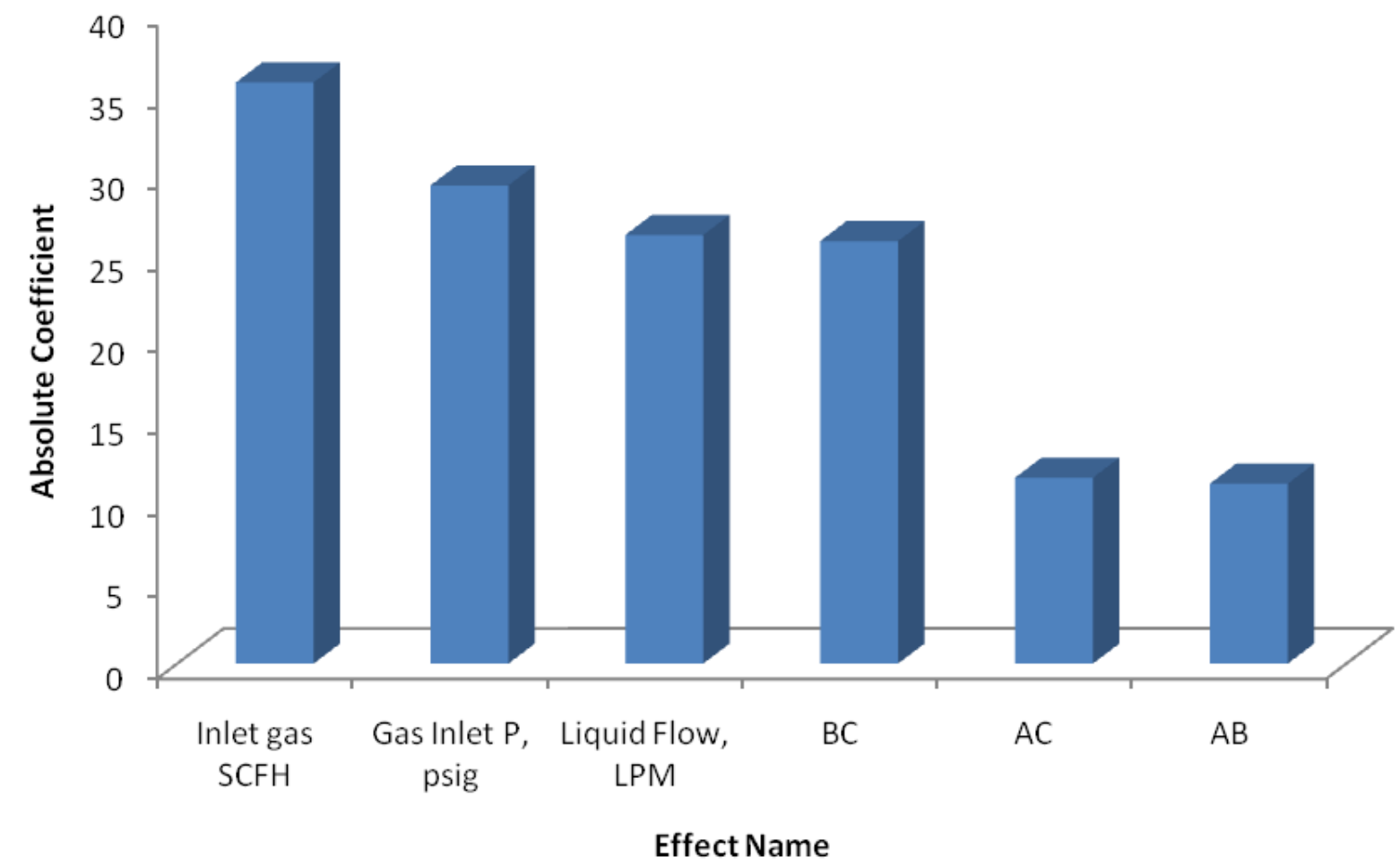

Figure 25. Pareto chart for variables influencing $\% \mathrm{CO}_{2}$ removal in membrane contactor

These data were also analyzed by the design of experiment method. The dependent variable was $\% \mathrm{CO}_{2}$ Removal and the Gas Inlet P, (psig), the Liquid Flow, (LPM) and the Inlet gas SCFH were the independent variables. The analysis shows that the $\% \mathrm{CO}_{2}$ Removal is a function of the variables shown in the figure above. The figure also shows that second order variables such as the product of Gas inlet $\mathrm{P}$ with Liquid flow also influence the $\% \mathrm{CO}_{2}$ Removal.

Modules with higher intrinsic $\mathrm{CO}_{2}$ permeance were also tested and the test results are summarized below. 
Table 12. Membrane contactor $\mathrm{CO}_{2}$ removal tests using water as solvent (Module 2PG285)

\begin{tabular}{|c|c|c|c|c|c|c|c|c|c|c|c|c|c|c|}
\hline $\begin{array}{l}\mathrm{CO}_{2} \\
\text { Flow, } \\
\text { SLPM }\end{array}$ & $\begin{array}{c}\mathrm{N}_{2} \text { Flow } \\
\text { SCFH }\end{array}$ & $\begin{array}{l}\text { Liquid } \\
\text { Flow, } \\
\text { L/min }\end{array}$ & $\begin{array}{c}\text { Gas } \\
\text { Inlet, } F\end{array}$ & $\begin{array}{c}\text { Gas } \\
\text { Outlet, } \\
\text { F }\end{array}$ & $\begin{array}{l}\text { Liquid } \\
\text { Inlet, } \mathrm{F}\end{array}$ & $\begin{array}{c}\text { Liquid } \\
\text { Outlet, } \mathrm{F}\end{array}$ & $\begin{array}{c}\text { Gas } \\
\text { Inlet, } \\
\text { psig }\end{array}$ & $\begin{array}{c}\text { Gas } \\
\text { Outlet, } \\
\text { psig }\end{array}$ & $\begin{array}{l}\text { Liquid } \\
\text { Inlet, } \\
\text { psig }\end{array}$ & $\begin{array}{c}\text { Inlet } \\
\mathrm{CO}_{2}, \%\end{array}$ & $\begin{array}{l}\text { Outlet } \\
\mathrm{CO}_{2}, \%\end{array}$ & $\begin{array}{l}\text { Total } \\
\text { Inlet } \\
\text { Gas, } \\
\text { SCFH }\end{array}$ & $\begin{array}{c}\text { Total } \\
\text { Outlet } \\
\text { Gas, } \\
\text { SCFH }\end{array}$ & $\begin{array}{c}\% \\
\text { Removal }\end{array}$ \\
\hline 18.7 & 53.9 & 1.4 & 69.5 & 71.4 & 75.0 & 78.0 & 501 & 493 & 507 & 39.6 & 26.5 & 93.4 & 80.3 & 42.5 \\
\hline 9.5 & 25.5 & 1.4 & 68.7 & 70.1 & 75.0 & 77.8 & 501 & 494 & 507 & 42.2 & 18.9 & 45.5 & 34.4 & 66.1 \\
\hline 9.4 & 25.4 & 1.4 & 69.6 & 68.7 & 58.1 & 61.5 & 501 & 494 & 507 & 42.8 & 15.4 & 45.4 & 32.6 & 74.1 \\
\hline 18.9 & 55.2 & 1.4 & 69.3 & 66.6 & 58.1 & 61.5 & 501 & 494 & 507 & 39.9 & 24.1 & 95.3 & 79.4 & 49.7 \\
\hline
\end{tabular}

The data shown above were obtained using water as a physical solvent and using a test matrix of changing inlet total gas flow, and inlet solvent temperature. The calculated mass transfer coefficients are shown below:

Table 13. Mass transfer coefficients from test results in Table 12.

\begin{tabular}{|c|c|c|c|c|c|c|c|c|c|}
\hline $\begin{array}{c}\mathrm{mol} / \mathrm{min} \mathrm{CO}_{2} \\
\text { Removed }\end{array}$ & $\begin{array}{c}\text { Inlet } \mathrm{CO}_{2} \\
\mathrm{P}, \mathrm{psi}\end{array}$ & $\begin{array}{c}\text { Outlet } \\
\mathrm{CO}_{2} \mathrm{P} \\
\text { psi }\end{array}$ & $\begin{array}{c}\text { Mean } \\
\mathrm{CO}_{2} \mathrm{P}, \\
\text { psi }\end{array}$ & $\begin{array}{c}\mathrm{K}_{\mathrm{G}} \\
\mathrm{mol} /\left(\mathrm{m}^{2} \cdot \mathrm{hr} . \mathrm{Kpa}\right)\end{array}$ & $\begin{array}{c}\mathrm{K}_{\mathrm{G}} \mathrm{a} \\
\mathrm{mol} /\left(\mathrm{m}^{3} \cdot \mathrm{hr} \cdot \mathrm{Kpa}\right)\end{array}$ & $\mathrm{K}_{\mathrm{G}}, \mathrm{cm} / \mathrm{s}$ & $\begin{array}{c}\mathrm{K}_{\mathrm{G}} \mathrm{a}, \\
1 / \mathrm{s}\end{array}$ & $\begin{array}{c}\mathrm{CO}_{2} \text { Removal } \\
\text { Rate } \\
\mathrm{kg} /\left(\mathrm{m}^{2} . \mathrm{hr}\right)\end{array}$ & $\begin{array}{c}\text { Total } \\
\text { Gas } \\
\text { Treated, } \\
\text { SCFH }\end{array}$ \\
\hline 0.331 & 203.9 & 134.3 & 169.1 & 0.142 & 330.9 & 0.0089 & 0.209 & 7.29 & 93.4 \\
\hline 0.267 & 217.67 & 96.1 & 156.8 & 0.123 & 287.8 & 0.0078 & 0.182 & 5.85 & 45.5 \\
\hline 0.303 & 220.7 & 78.3 & 149.5 & 0.147 & 342.8 & 0.0093 & 0.216 & 6.67 & 45.4 \\
\hline 0.398 & 205.7 & 122.66 & 164.1 & 0.175 & 409.4 & 0.0111 & 0.258 & 8.72 & 95.3 \\
\hline
\end{tabular}

The above data show that the calculated mass transfer coefficients are below the intrinsic permeance of the bare membrane used to construct the contactor module indicating liquid-side mass transfer resistance. Liquid side mass transfer resistance is generally caused by the concentration polarization due to inadequate liquid velocity, high solvent viscosity, and slow diffusion of the absorbing species. On the other hand, the overall mass transfer coefficient $\mathrm{K}_{\mathrm{G}} \mathrm{a}$ of $0.25(\mathrm{sec})^{-1}$ is more than 7 times higher than that shown in Table 11.

Test results are summarized below for module 2PG 300 


\section{gti}

Table 14. Membrane contactor $\mathrm{CO}_{2}$ removal tests using water as solvent (2PG300)

\begin{tabular}{|c|c|c|c|c|c|c|c|c|c|c|c|c|c|c|}
\hline $\begin{array}{l}\mathrm{CO}_{2} \\
\text { Flow, } \\
\text { SLPM }\end{array}$ & $\begin{array}{c}\mathrm{N}_{2} \text { Flow } \\
\text { SCFH }\end{array}$ & $\begin{array}{l}\text { Liquid } \\
\text { Flow, } \\
\text { L/min }\end{array}$ & $\begin{array}{l}\text { Gas } \\
\text { Inlet, } \\
{ }^{\circ} \mathrm{F}\end{array}$ & $\begin{array}{l}\text { Gas } \\
\text { Outlet, } \\
{ }^{\circ} \mathrm{F}\end{array}$ & $\begin{array}{l}\text { Liquid } \\
\text { Inlet, } \\
{ }^{\circ} \mathrm{F}\end{array}$ & $\begin{array}{l}\text { Liquid } \\
\text { Outlet, } \\
{ }^{\circ} \mathrm{F}\end{array}$ & $\begin{array}{c}\text { Gas } \\
\text { Inlet, } \\
\text { psig }\end{array}$ & $\begin{array}{c}\text { Gas } \\
\text { Outlet, } \\
\text { psig }\end{array}$ & $\begin{array}{c}\text { Liquid } \\
\text { Inlet, } \\
\text { psig }\end{array}$ & $\begin{array}{c}\text { Inlet } \\
\mathrm{CO}_{2}, \%\end{array}$ & $\begin{array}{l}\text { Outlet } \\
\mathrm{CO}_{2}, \%\end{array}$ & $\begin{array}{l}\text { Total Inlet } \\
\text { Gas, SCFH }\end{array}$ & $\begin{array}{c}\text { Total } \\
\text { Outlet Gas, } \\
\text { SCFH }\end{array}$ & $\begin{array}{c}\% \\
\text { Removal }\end{array}$ \\
\hline 2.5 & 7.7 & 1.31 & 77.9 & 77.5 & 75.3 & 77.6 & 500 & 493 & 510 & 39 & 2.45 & 13.0 & 8.4 & 95.9 \\
\hline 3.01 & 9.8 & 1.31 & 68.1 & 68.4 & 75 & 78 & 499 & 492 & 510 & 40.5 & 3.36 & 16.2 & 9.5 & 95.1 \\
\hline 4.00 & 12.9 & 1.30 & 67.3 & 68.2 & 75 & 77.7 & 499 & 492 & 510 & 39.9 & 11.6 & 21.4 & 13.6 & 81.6 \\
\hline 3.50 & 11.5 & 1.30 & 67.6 & 68.4 & 75 & 77.6 & 501 & 492 & 510 & 39.3 & 10.3 & 18.9 & 12.1 & 83.2 \\
\hline 3.50 & $\begin{array}{l}11.8 \\
(\mathrm{He})\end{array}$ & 1.30 & 68.6 & 69 & 75 & 77.6 & 499 & 492 & 511 & 38.1 & 3.5 & 19.2 & 12.3 & 94.1 \\
\hline
\end{tabular}

The data shown above were obtained using water as a physical solvent and using a test matrix of changing inlet total gas flow, and inlet solvent temperature. The calculated mass transfer coefficients are shown below:

\section{Table 15. Mass transfer coefficients from test results in Table 14.}

\begin{tabular}{|c|c|c|c|c|c|c|c|c|c|}
\hline $\begin{array}{c}\mathrm{mol} / \mathrm{min} \\
\mathrm{CO}_{2} \\
\text { Removed }\end{array}$ & $\begin{array}{c}\text { Inlet } \\
\mathrm{CO}_{2} \mathrm{P}, \\
\mathrm{psi}\end{array}$ & $\begin{array}{c}\text { Outlet } \\
\mathrm{CO}_{2} \mathrm{P}, \\
\mathrm{psi}\end{array}$ & $\begin{array}{c}\text { Mean } \\
\mathrm{CO}_{2} \mathrm{P}, \\
\mathrm{psi}\end{array}$ & $\begin{array}{c}\mathrm{K}_{\mathrm{G}} \\
\mathrm{mol} /\left(\mathrm{m}^{2} . \mathrm{hr} . \mathrm{Kpa}\right)\end{array}$ & $\begin{array}{c}\mathrm{K}_{\mathrm{G}} \mathrm{a}, \\
\mathrm{mol} /\left(\mathrm{m}^{3} \cdot \mathrm{hr} . \mathrm{Kpa}\right)\end{array}$ & $\begin{array}{c}\mathrm{K}_{\mathrm{G}}, \\
\mathrm{cm} / \mathrm{s}\end{array}$ & $\begin{array}{c}\mathrm{K}_{\mathrm{G}} \mathrm{a}, \\
1 / \mathrm{s}\end{array}$ & $\begin{array}{c}\mathrm{CO}_{2} \text { Removal Rate } \\
\mathbf{k g} /\left(\mathrm{m}^{2} . \mathrm{hr}\right)\end{array}$ & $\begin{array}{c}\text { Total Gas Treated, } \\
\mathrm{SCFH}\end{array}$ \\
\hline 0.102 & 195.0 & 12.1 & 103.5 & 0.0387 & 90.5 & 0.00244 & 0.0571 & 1.22 \\
\hline 0.131 & 202.1 & 16.5 & 109.3 & 0.0472 & 110.4 & 0.00298 & 0.0696 & 1.57 \\
\hline 0.147 & 199.1 & 57.1 & 128.1 & 0.0450 & 105.2 & 0.00284 & 0.0664 & 1.75 \\
\hline 0.130 & 196.9 & 50.7 & 123.8 & 0.0412 & 96.4 & 0.00260 & 0.0608 & 1.55 \\
\hline 0.145 & 190.1 & 17.2 & 103.7 & 0.0549 & 128.4 & 0.00346 & 0.0810 & 1.4 & 1.73 \\
\hline
\end{tabular}

Note: the last data point in the above Tables was obtained where the inert gas was Helium instead of $\mathrm{N}_{2}$. As compared to the $\mathrm{N}_{2}$ data, the Helium data suggests that the membrane contactor performs better with Helium as the inert gas. Helium is used in place of hydrogen due to safety concerns. Therefore, the data obtained with $\mathrm{N}_{2}$ when used to perform process economics represent a conservative estimate. 
The above data show that the calculated mass transfer coefficients are still below the intrinsic permeance of the bare membrane indicating liquid-side mass transfer resistance. Liquid mass transfer resistance is generally caused by the concentration polarization due to inadequate liquid velocity, high solvent viscosity, and slow diffusion of the absorbing species.

We have also investigated other solvents such as chilled methanol (Rectisol®). The results of these tests are summarized below. 
Table 16. Membrane contactor $\mathrm{CO}_{2}$ removal tests using methanol as solvent.

\begin{tabular}{|c|c|c|c|c|c|c|c|c|c|c|c|c|c|c|}
\hline $\begin{array}{l}\mathrm{CO}_{2} \\
\text { Flow, } \\
\text { SLPM }\end{array}$ & $\begin{array}{l}\mathrm{N}_{2} \text { Flow } \\
\text { SCFH }\end{array}$ & $\begin{array}{l}\text { Liquid } \\
\text { Flow, } \\
\text { L/min }\end{array}$ & $\begin{array}{l}\text { Gas } \\
\text { Inlet, } \\
{ }^{\circ} \mathrm{F}\end{array}$ & $\begin{array}{c}\text { Gas } \\
\text { Outlet, } \\
{ }^{\circ} \mathrm{F}\end{array}$ & $\begin{array}{l}\text { Liquid } \\
\text { Inlet, } \\
{ }^{\circ} \mathrm{F}\end{array}$ & $\begin{array}{l}\text { Liquid } \\
\text { Outlet, } \\
{ }^{\circ} \mathrm{F}\end{array}$ & $\begin{array}{c}\text { Gas } \\
\text { Inlet, } \\
\text { psig }\end{array}$ & $\begin{array}{l}\text { Gas } \\
\text { Outlet, } \\
\text { psig }\end{array}$ & $\begin{array}{l}\text { Liquid } \\
\text { Inlet, } \\
\text { psig }\end{array}$ & $\begin{array}{c}\text { Inlet } \\
\mathrm{CO}_{2}, \%\end{array}$ & $\begin{array}{l}\text { Outlet } \\
\mathrm{CO}_{2}, \%\end{array}$ & $\begin{array}{l}\text { Total Inlet } \\
\text { Gas, SCFH }\end{array}$ & $\begin{array}{c}\text { Total } \\
\text { Outlet Gas, } \\
\text { SCFH }\end{array}$ & $\begin{array}{c}\% \\
\text { Removal }\end{array}$ \\
\hline 17.7 & 57.7 & 0.66 & 73.2 & 67.5 & 32.1 & 45.5 & 501 & 492 & 505 & 36.9 & 14.2 & 95.2 & 69.1 & 72.1 \\
\hline 8.07 & 23.7 & 0.41 & 76.3 & 71.5 & 23.4 & 36.3 & 500 & 493 & 495 & 36.6 & 9.5 & 40.8 & 31.1 & 80.2 \\
\hline 2.15 & 7.25 & 0.41 & 74.3 & 73.2 & 20.0 & 32.9 & 499 & 492 & 501 & 37.0 & 0.1 & 11.8 & 7.8 & 99.8 \\
\hline 4.99 & 14.2 & 0.41 & 74.8 & 73.2 & 20.5 & 36.3 & 500 & 493 & 499 & 37.7 & 3.2 & 24.8 & 17.7 & 93.9 \\
\hline
\end{tabular}

Table 17. Mass transfer coefficients from test results in Table 16

\begin{tabular}{|c|c|c|c|c|c|c|c|c|c|}
\hline $\begin{array}{c}\mathrm{mol} / \mathrm{min} \\
\mathrm{CO}_{2} \\
\text { Removed }\end{array}$ & $\begin{array}{l}\text { Inlet } \mathrm{CO}_{2} \\
\mathrm{P}, \mathrm{psi}\end{array}$ & $\begin{array}{l}\text { Outlet } \\
\mathrm{CO}_{2} \mathrm{P}, \\
\text { psi }\end{array}$ & $\begin{array}{c}\text { Mean } \\
\mathrm{CO}_{2} \mathrm{P}, \mathrm{psi}\end{array}$ & $\begin{array}{c}\mathrm{K}_{\mathrm{G}} \\
\mathrm{mol} /\left(\mathrm{m}^{2} \cdot \mathrm{hr} \cdot \mathrm{Kpa}\right)\end{array}$ & $\begin{array}{c}\mathrm{K}_{\mathrm{G}} \mathrm{a} \\
\mathrm{mol} /\left(\mathrm{m}^{3} \cdot \mathrm{hr} \cdot \mathrm{Kpa}\right)\end{array}$ & $\begin{array}{c}\mathrm{K}_{\mathrm{G}} \\
\mathrm{cm} / \mathrm{s}\end{array}$ & $\begin{array}{l}\mathrm{K}_{\mathrm{G}} \mathrm{a} \\
1 / \mathrm{s}\end{array}$ & $\begin{array}{c}\mathrm{CO}_{2} \text { Removal } \\
\text { Rate } \\
\mathrm{kg} /\left(\mathrm{m}^{2} . \mathrm{hr}\right)\end{array}$ & $\begin{array}{c}\text { Total Gas } \\
\text { Treated, SCFH }\end{array}$ \\
\hline 0.53 & 184.9 & 69.8 & 127.4 & 0.15 & 309.9 & 0.0098 & 0.195 & 5.80 & 95.2 \\
\hline 0.25 & 183.0 & 46.8 & 114.9 & 0.08 & 162.3 & 0.0051 & 0.102 & 2.79 & 40.8 \\
\hline 0.09 & 184.6 & 0.5 & 92.6 & 0.04 & 73.3 & 0.0023 & 0.046 & 1.12 & 11.8 \\
\hline 0.19 & 188.5 & 15.8 & 102.1 & 0.07 & 134.0 & 0.0042 & 0.085 & 2.17 & 24.8 \\
\hline
\end{tabular}

These data show that the methanol is a very good solvent for $\mathrm{CO}_{2}$ removal with higher mass transfer coefficient than that of water as a solvent under similar conditions. We were unable to reach the $-40^{\circ} \mathrm{F}$ temperature conditions due to cooling limitations and the high pressure diaphragm pump could not pump at temperatures below $20^{\circ} \mathrm{F}$ to duplicate the commercial Rectisol $\circledast$ absorption conditions . 


\section{Task 8. Bench Scale Testing Using Slipstream from GTI's FFTF Gasifier}

In this task, bench scale testing was conducted using a slipstream from GTI's FFTF gasifier. These tests were conducted under realistic syngas conditions, the feed gas contained typical impurities and the test thus demonstrated the influence of these impurities on membrane contactor performance. Membrane contactor performance test duration was limited by the availability of FFTF on-line time. Initially we anticipated a one week test period with FFTF gasifier feed . The contractor prepared a test plan for conducting these slipstream tests. The test plan was provided to DOE for review, prior to conducting tests.

Project Activities/Products: The design of the test equipment was completed, all parts for test system construction ordered and the test rig for testing with gasifier feed built. The test rig has been designed to accommodate testing of different types of contactor modules with the GTI's gasifier feed. The process flow scheme is shown in Figure 26 below.

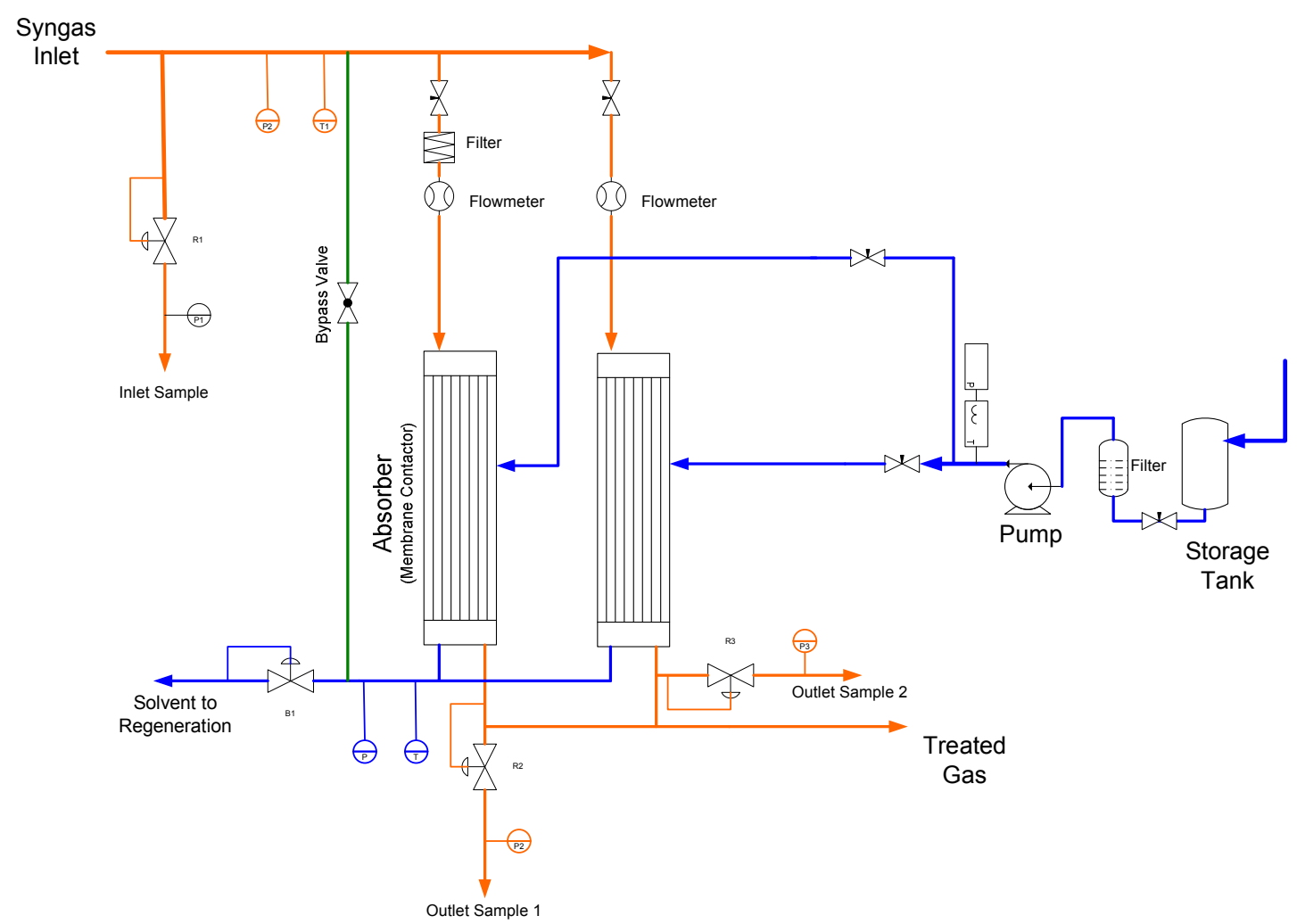

Figure 26. Membrane contactor test process flow diagram for FFTF syngas cleanup .

Two membrane contactor modules 2PG307 and 2PG308 (size 2-inch diameter by 12-inch long) were tested. Module 2PG 308 was tested with a particulate filter and 2PG307 without filter. The test lasted about 100 hours. The performance of the two modules was monitored throughout the test to determine the effect of particulates on the membrane performance. Test timeline of the two modules are shown below: 
Table 18. Summary of results from tests conducted using the FFTF gasifier syngas feed.

2PG308 with filter in line:

Set point 1

\begin{tabular}{|c|c|c|c|c|c|}
\hline Date & Start Time & End Time & Sample & $\begin{array}{c}\text { Avg. [CO2- } \\
\text { \% vol }\end{array}$ & $\begin{array}{c}\text { FI-1, } \\
\text { SLPM }\end{array}$ \\
\hline $10 / 22$ & 2234 & 0724 & Inlet & 21.80 & - \\
\hline \multirow{4}{*}{$10 / 23$} & 0727 & 0946 & 308 outlet & 3.61 & $5-8.9$ \\
\cline { 2 - 6 } & 1310 & 1409 & Inlet & 21.03 & 5 \\
\cline { 2 - 6 } & 1452 & 1656 & 308 outlet & 1.75 & $4.5-5$ \\
\cline { 2 - 6 } & 1800 & 1951 & Inlet & 21.43 & 5 \\
\cline { 2 - 6 } & 1954 & 2103 & 308 outlet & 1.03 & 5 \\
\hline
\end{tabular}

Set point $2 a$ - No data

Set point $2 b$ :

\begin{tabular}{|c|l|l|l|l|l|}
\hline Date & Start Time & End Time & \multicolumn{1}{|c|}{ Sample } & $\begin{array}{c}\text { Avg. [CO2- } \\
\text { ] \%vol }\end{array}$ & \multicolumn{1}{c|}{$\begin{array}{c}\text { FI-1, } \\
\text { SLPM }\end{array}$} \\
\hline $10 / 24$ & 2104 & 0437 & 308 outlet & 6.91 & $?$ \\
\hline \multirow{2}{*}{$10 / 25$} & 0737 & 1147 & 308 outlet & 4.83 & $6.2-5.4$ \\
\cline { 2 - 6 } & 1149 & 1304 & Inlet & 24.20 & $5.4-3$ \\
\hline
\end{tabular}

Set point 3a- No Data

Set Point 3b

\begin{tabular}{|c|l|l|l|l|l|}
\hline Date & Start Time & End Time & Sample & $\begin{array}{c}\text { Avg. [CO2- } \\
\text { ] \%vol }\end{array}$ & \multicolumn{1}{c|}{$\begin{array}{c}\text { FI-1, } \\
\text { SLPM }\end{array}$} \\
\hline \multirow{2}{*}{$10-26$} & 0458 & 1207 & 308 outlet & 11.41 & $6-4$ \\
\cline { 2 - 6 } & 1309 & 1401 & 308 outlet & 13.78 & 4 \\
\hline
\end{tabular}

Set Point 4

\begin{tabular}{|c|l|l|l|l|l|}
\hline Date & Start Time & End Time & \multicolumn{1}{|c|}{ Sample } & $\begin{array}{c}\text { Avg. [CO2- } \\
\text { ] \%vol }\end{array}$ & \multicolumn{1}{c|}{$\begin{array}{c}\text { FI-1, } \\
\text { SLPM }\end{array}$} \\
\hline \multirow{2}{*}{$10 / 26$} & 1840 & 2121 & 308 outlet & 9.16 & 4 \\
\cline { 2 - 6 } & 2135 & 2235 & Inlet & 20.32 & $?$ \\
\hline
\end{tabular}

2PG307 without filter in line:

Set Point 1

\begin{tabular}{|c|l|l|l|l|l|}
\hline Date & Start Time & End Time & \multicolumn{1}{|c|}{ Sample } & $\begin{array}{c}\text { Avg. [CO2- } \\
\text { j \%vol }\end{array}$ & \multicolumn{1}{c|}{$\begin{array}{c}\text { FI-2, } \\
\text { SLPM }\end{array}$} \\
\hline \multirow{3}{*}{$10 / 22$} & 2234 & 0724 & Inlet & 21.80 & - \\
\hline \multirow{5}{*}{$10 / 23$} & 0953 & 1303 & 307 outlet & 15.74 & $8.7-8.8$ \\
\cline { 2 - 6 } & 1310 & 1409 & Inlet & 21.03 & 5 \\
\cline { 2 - 6 } & 1659 & 1750 & 307 outlet & 14.30 & 4 \\
\cline { 2 - 6 } & 1800 & 1951 & Inlet & 21.43 & 4 \\
\cline { 2 - 6 } & 2106 & 2147 & 307 outlet & 14.07 & 4 \\
\hline
\end{tabular}

Set Point $2 a$

\begin{tabular}{|c|l|l|l|l|l|}
\hline Date & Start Time & End Time & \multicolumn{1}{|c|}{ Sample } & $\begin{array}{c}\text { Avg. [CO2- } \\
\text { \% \%ol }\end{array}$ & \multicolumn{1}{c|}{$\begin{array}{c}\text { FI-2, } \\
\text { SLPM }\end{array}$} \\
\hline \multirow{2}{*}{$10 / 24$} & 1201 & 1329 & 307 outlet & 9.72 & 2.5 \\
\cline { 2 - 6 } & 1337 & 1801 & Inlet & 23.81 & $2.5-4$ \\
\hline
\end{tabular}

DE-FE-0000646 Final Technical Report 
Set Point $2 b$

\begin{tabular}{|c|l|l|l|l|l|}
\hline Date & Start Time & End Time & \multicolumn{1}{|c|}{ Sample } & $\begin{array}{c}\text { Avg. [CO2- } \\
\text { ] \%vol }\end{array}$ & \multicolumn{1}{c|}{$\begin{array}{c}\text { FI-2, } \\
\text { SLPM }\end{array}$} \\
\hline \multirow{2}{*}{$10 / 24$} & 2000 & 2059 & 307 outlet & 17.47 & $?$ \\
\hline \multirow{3}{*}{$10 / 25$} & 0538 & 0731 & 307 outlet & 14.95 & $9.5-10.3$ \\
\cline { 2 - 6 } & 1149 & 1304 & Inlet & 24.20 & $8.5-2$ \\
\cline { 2 - 6 } & 1308 & 1703 & 307 outlet & 14.22 & $2.4-6$ \\
\hline
\end{tabular}

Set point $3 a$ - No Data

Set Point $3 b$

\begin{tabular}{|c|l|l|l|c|c|}
\hline Date & Start Time & End Time & Sample & $\begin{array}{c}\text { Avg. [CO2- } \\
\text { ] \% vol }\end{array}$ & $\begin{array}{c}\text { FI-2, } \\
\text { SLPM }\end{array}$ \\
\hline $10 / 26$ & 1209 & 1307 & 307 outlet & 17.02 & $7-3$ \\
\hline
\end{tabular}

Set Point 4- No Data

The $\mathrm{CO}_{2}$ removal performance of the modules is shown in Figure 27. This figure and the data listed in the above table show that module 2PG308 with in-line filter maintained the $90 \%$ $\mathrm{CO}_{2}$ removal target during the first two days of tests, whereas module 2PG307 without filter could never reach the $90 \%$ removal rate. 


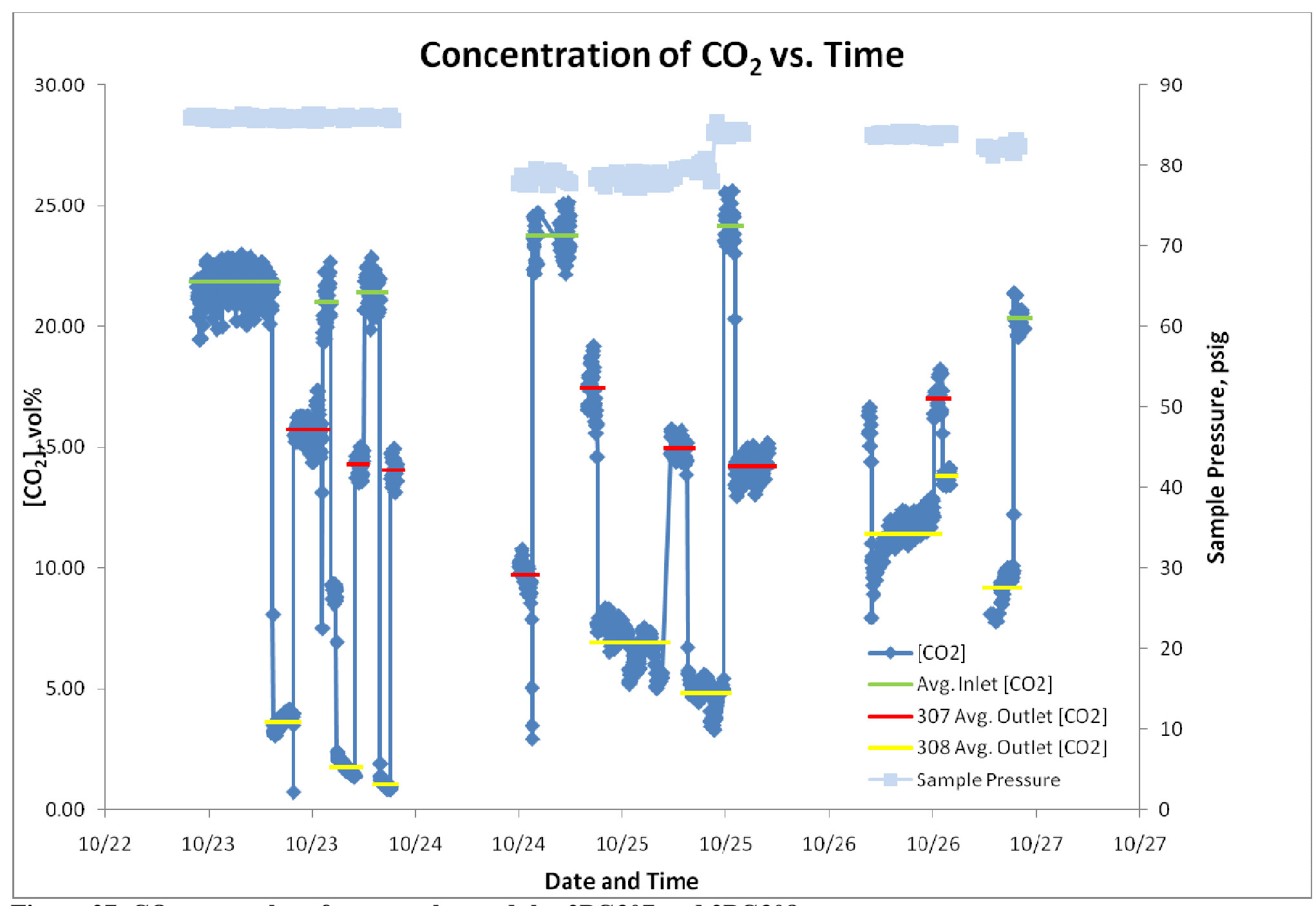

Figure 27. $\mathrm{CO}_{2}$ removal performance by modules $2 \mathrm{PG307}$ and 2PG308. 


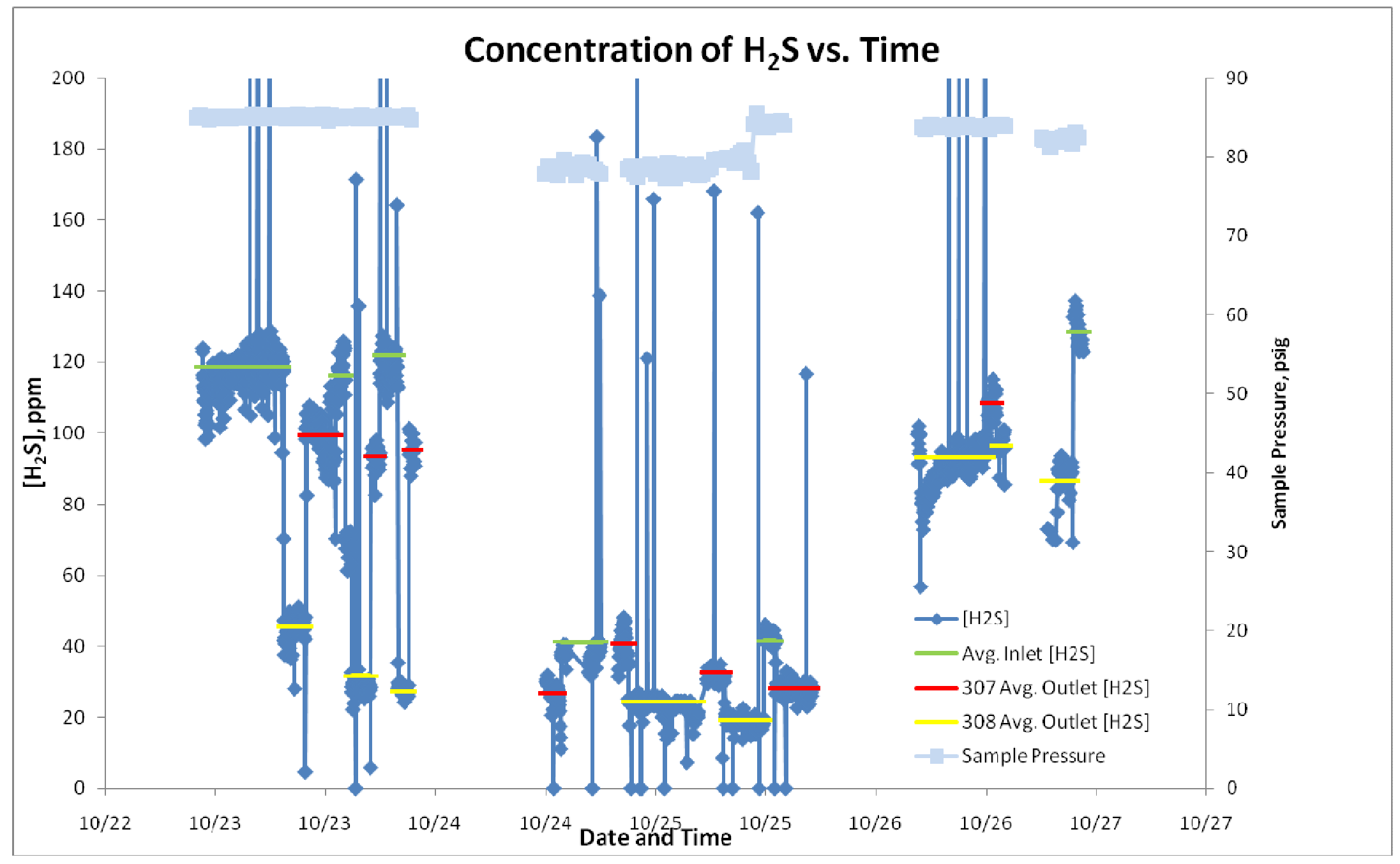

Figure 28. $\mathrm{H}_{2} \mathrm{~S}$ removal performance by modules 2 PG307 and 2PG308. 
It was observed during the test that the filter removed not only particulates but also mists in the syngas. It was known that liquid water in the gas stream is detrimental to the performance of the membrane contactor. The present tests confirm that particulates and mists must be removed from the syngas before it reaches the membrane contactor.

The data shown in Figure 28 are $\mathrm{H}_{2} \mathrm{~S}$ removal performances of the two modules. The tests were not designed for $\mathrm{H}_{2} \mathrm{~S}$ removal. However, since we used DI water as the physical solvent for $\mathrm{CO}_{2}$ removal, it has provided some $\mathrm{H}_{2} \mathrm{~S}$ removal capacity. For complete $\mathrm{H}_{2} \mathrm{~S}$ removal prior to $\mathrm{CO}_{2}$ removal, one stage of $\mathrm{H}_{2} \mathrm{~S}$ removal using solvents that are more $\mathrm{H}_{2} \mathrm{~S}$ selective is required.

\section{Task 9. Refine Economic Evaluation}

In this task, the process economics will be updated based on the optimized bench test results. The study will address membrane contactor costs as well at the capture costs. The study will be done in sufficient detail to permit a third party economic evaluation of the process and its scale-up and commercial potential.

\section{Project Activities/Products:}

The 2-stages of membrane contactor system replaces the 2-stages of Selexol ${ }^{\mathrm{TM}}$ system. The first stage is for $\mathrm{H} 2 \mathrm{~S}$ removal and the second stage for $\mathrm{CO} 2$ removal. The cost analysis takes into account the increase in the total plant cost with these additions. The 2-stages of the membrane contactor process is depicted in Figure 29.

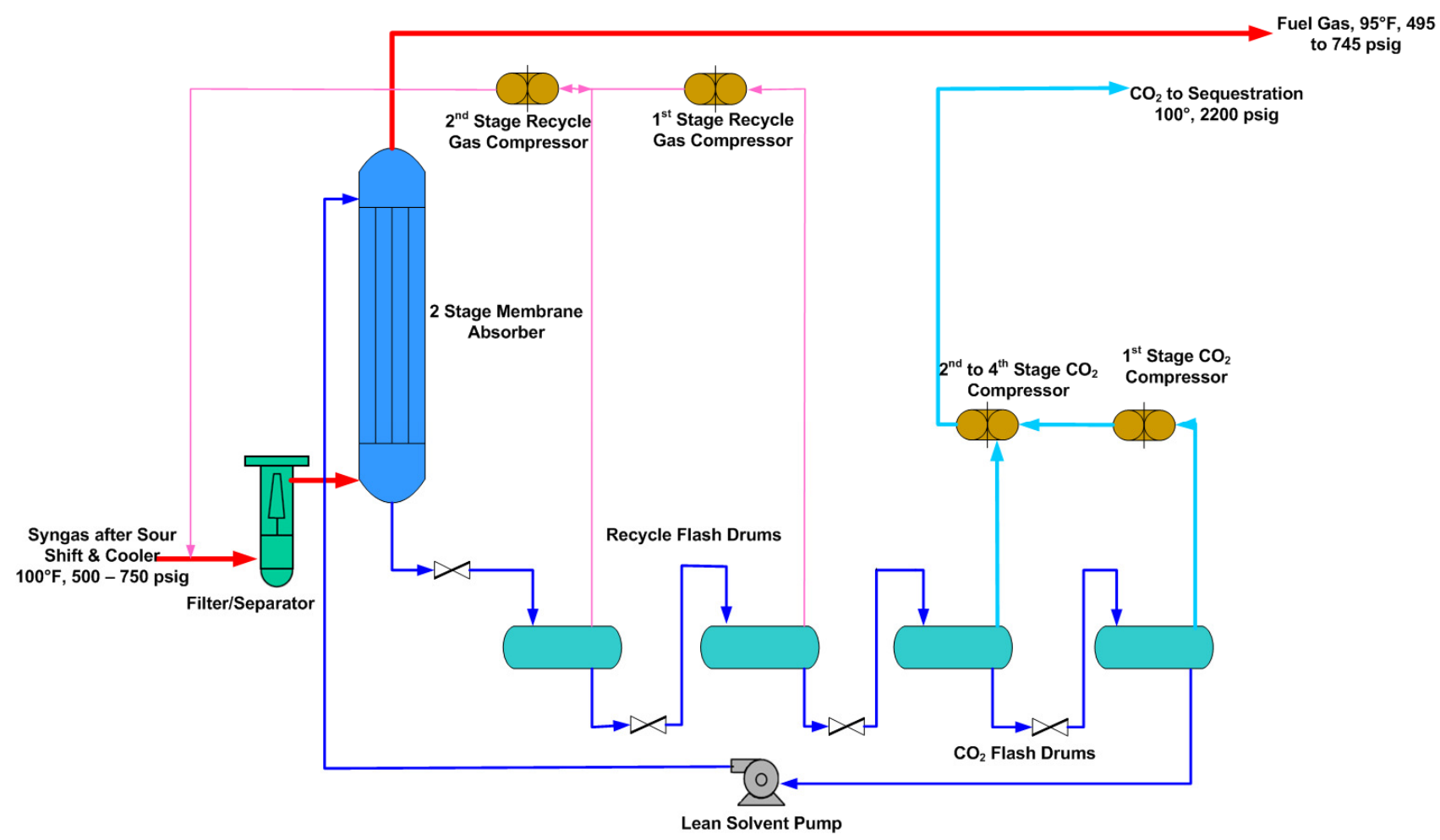

Figure 29. 2-stages of membrane contactor process for syngas clean up. 
Process economics modeling was carried out assuming the substitution of a membrane contactor for Selexol ${ }^{\mathrm{TM}} \mathrm{CO}_{2}$ absorption

\section{$\underline{\text { Design Basis }}$}

- We have used the cost estimates for the DOE Cases 1 (Cost estimation with no $\mathrm{CO}_{2}$ capture) and Case 2 (Cost estimation with $\mathrm{CO}_{2}$ capture) ${ }^{2}$ as the Base Case that represents current benchmark technology for electric power generation with $\mathrm{CO}_{2}$ removal (including transport, storage and monitoring) from syngas generated in a nominal $550 \mathrm{MW}_{\mathrm{e}}$ IGCC plant.

\section{Economic Evaluation-Results and Discussion}

\section{Estimates on CAPEX}

The changes in CAPEX are estimated from a cost of membrane at $\$ 100 / \mathrm{m}^{2}$. The CAPEX of the membrane contactor unit is based on the experimentally obtained $\mathrm{CO}_{2}$ removal flux $\left(1.5 \mathrm{~kg} / \mathrm{m}^{2} / \mathrm{hr}\right.$ using water as a solvent). Water is used as solvent because of its low cost and environmental friendliness although methanol had a much higher mass transfer coefficient in our laboratory tests. The total $\mathrm{CO}_{2}$ removed is the same as in Case and equals to $469,000 \mathrm{~kg} / \mathrm{hr}$. This would correspond to a total membrane area of about 300,000 square meters. For the base case design using this membrane contactor:

- The cost of the membrane system (woven PEEK hollow fiber membranes assembled in as a module and installed in a canister) has been assumed at $\$ 100 / \mathrm{m}^{2}$ (Jan., 2011\$).

- Total installed cost of the membrane unit (membrane system mounted to the skid) is assumed to be $1.4 \mathrm{x}$ cost of membrane system.

The changes in total CAPEX for the case relative to the DOE Case 2 are summarized in Table 19.

Table 19. Key changes in CAPEX (Yr 2006\$)

\begin{tabular}{|l|c|c|}
\hline \multicolumn{1}{|c|}{ Item } & $\begin{array}{c}\text { DOE Case 2 } \\
(2 \text {-stage Selexol }\end{array}$ & Membrane contactor \\
\cline { 3 - 3 } & +59 & Water solvent \\
\hline 2-stages of Selexol & - & - \\
\hline Membrane unit, \$MM & - & 42 \\
\hline Other equipment, \$MM & 20 & 20 \\
\hline $\begin{array}{l}\text { Total CAPEX for the } \mathrm{CO}_{2} \text { capture } \\
\text { unit, \$MM }\end{array}$ & 79 & 62 \\
\hline
\end{tabular}

\section{Estimates on Plant Performance}

The power plant performance of DOE Cases 1, 2 and Membrane Contactor case is summarized in Table 20. 
Table 20. Estimated performance and cost results for IGCC Cases

\begin{tabular}{|l|c|c|c|}
\hline \hline \multicolumn{1}{|c|}{ Design Case } & DOE Case 1 & DOE Case 2 & Membrane contactor \\
\hline $\mathrm{CO}_{2}$ Capture & No & Yes & Yes \\
\hline Gross Power Output $\mathrm{kW}_{\mathrm{e}}$ & 770,350 & 744,960 & 762,017 \\
\hline Total auxiliaries, $\mathrm{kW}_{\mathrm{e}}$ & 130,100 & 189,285 & 189,285 \\
\hline $\begin{array}{l}\text { Gross gas turbine Power, } \\
\mathrm{kW}_{\mathrm{e}}\end{array}$ & 464,300 & 464,010 & 464,010 \\
\hline $\begin{array}{l}\text { Gross steam turbine } \\
\text { Power, } \mathrm{kW}_{\mathrm{e}}\end{array}$ & 289,900 & 274,690 & 279,750 \\
\hline Net power, $\mathrm{kW}$ & 614,250 & 555,675 & 572,732 \\
\hline & & & $1,710,780$ \\
\hline Total thermal input, $\mathrm{kWe}$ & $1,674,044$ & $1,710,780$ & 33.4 \\
\hline $\begin{array}{l}\text { Net plant efficiency, } \\
\text { HHV\% }\end{array}$ & 38.2 & 32.5 & \\
\hline
\end{tabular}

\section{Cost of Power Generation, mills/kWhr}

The key data on various levelized cost of electricity (LCOE) costs for the design cases are summarized in Table 21. For the membrane contactor case, the reduction in LCOE over the DOE Case 2 is about $8 \%$; this reflects an increase of LCOE by about $21 \%$ over the DOE Case 1 . The goal of $10 \%$ increase in LCOE from base Case 1 is not achieved by using the membrane contactor. However, the $21 \%$ increase in LCOE is a substantial improvement as compared with the $31.6 \%$ increase in LCOE as in DOE Case 2. Further decrease in LCOE over the base case is very difficult to obtain due to the reduction in the power generated by the steam turbine as a consequence of the $90 \%$ removal of $\mathrm{CO}_{2}$, due to the increase in power consumption by the $\mathrm{CO}_{2}$ removal system, and due to the power consumption by the $\mathrm{CO}_{2}$ compression system.

Table 21. LCOE of base case IGCC plants with and without $\mathrm{CO}_{2}$ capture compared with membrane contactor process for $\mathrm{CO}_{2}$ capture IGCC plant in 2006 \$.

\begin{tabular}{|c|c|c|c|c|c|}
\hline \multirow[b]{2}{*}{ Cost } & \multicolumn{3}{|c|}{ LCOE (\$/MW) } & \multirow{2}{*}{$\%$ Change from Case 1} & \multirow{2}{*}{$\%$ Change from Case 2} \\
\hline & Case 1 & Case 2 & $\begin{array}{l}\text { Membrane } \\
\text { Contactor } \\
\left(\$ 100 / \mathbf{m}^{2}\right) \\
\end{array}$ & & \\
\hline Capital & $\$ 45.28$ & $\$ 59.65$ & $\$ 51.85$ & $14.5 \%$ & $-13.1 \%$ \\
\hline Fixed & $\$ 6.05$ & $\$ 7.50$ & $\$ 7.28$ & $20.3 \%$ & $-2.9 \%$ \\
\hline Variable & $\$ 7.51$ & $\$ 9.35$ & $\$ 9.08$ & $20.9 \%$ & $-2.9 \%$ \\
\hline Coal & $\$ 19.36$ & $\$ 22.78$ & $\$ 22.12$ & $14.3 \%$ & $-2.9 \%$ \\
\hline $\mathrm{CO}_{2}$ & $\$ 0$ & $\$ 3.66$ & $\$ 4.18$ & & $14.1 \%$ \\
\hline Total & $\$ 78.20$ & $\$ 102.94$ & $\$ 94.50$ & $20.9 \%$ & $-8.2 \%$ \\
\hline
\end{tabular}




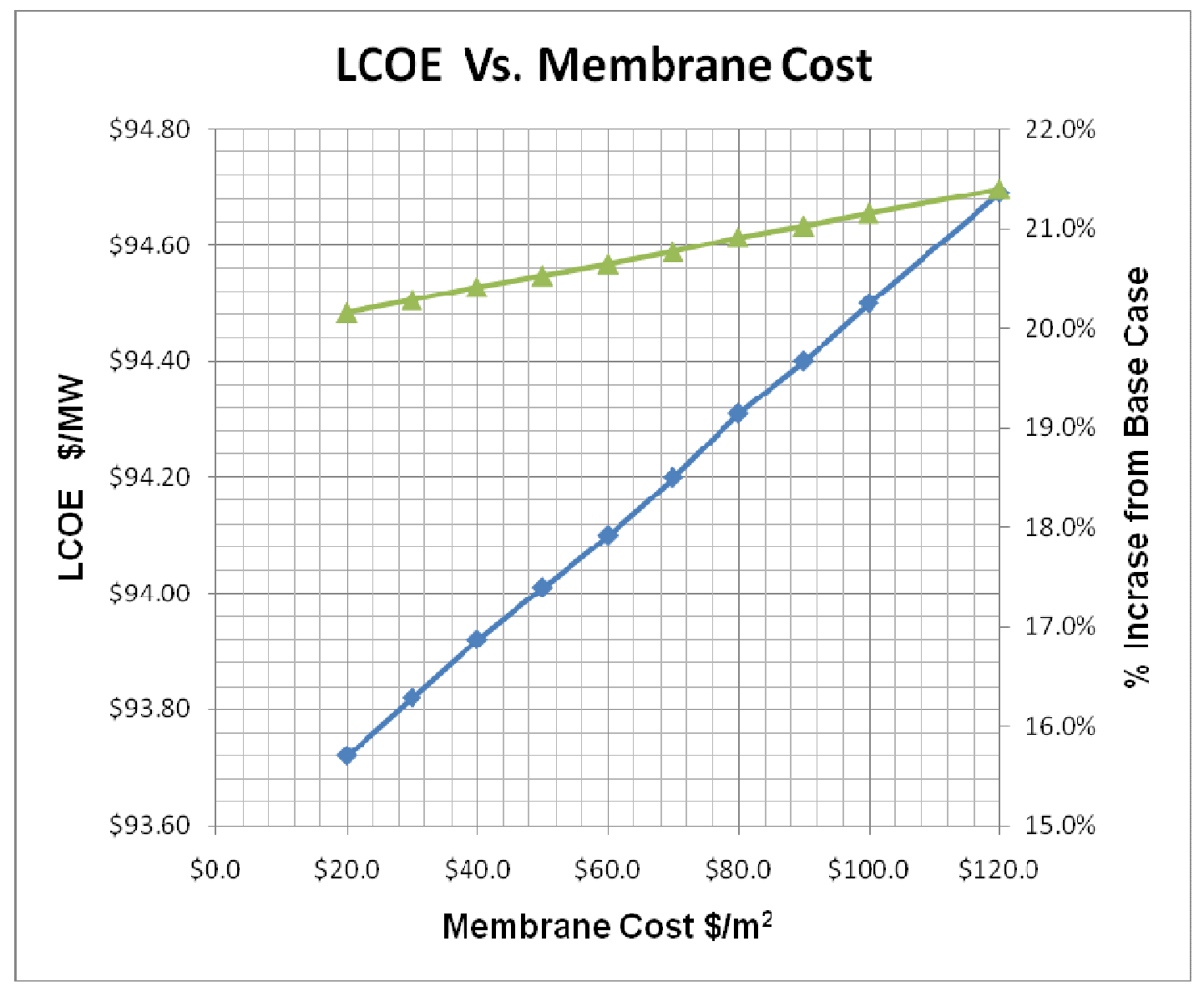

Figure 30. LCOE cost sensitivity as a function of membrane cost

Figure 30 shows the LCOE as a function of membrane cost. It is seen that the LCOE is not a very sensitive function of membrane cost. This is because the $\mathrm{CO}_{2}$ removal sub-system cost is only a very small part of the total power plant cost.

Modeling Results: The 1-D model can be used to predict the $\mathrm{CO}_{2}$ removal efficiency along the length of the fiber. $\mathrm{CO}_{2}$ removal for the two modules (2PG243 and 2PG285) with water as the solvent is given in Figure 30 and Figure 31. The physical properties are calculated using Electrolyte NRTL (E-NRTL) model from the Aspen Property simulator. The required Henry's law constant data for the system are from Penttila et al. (2011) ${ }^{9}$. Table 10 and Table 12 lists the experimental data points used in Figure 30 and Figure 31.. As can be seen, the predicted removal is close to the experimental values. However, in all cases it under predicts the outlet conditions. The model assumes constant linear gas velocity and isothermal conditions, and the prediction is based on inlet conditions and constant physical properties. Among the variables, the linear gas velocity is seen to be highly sensitive to the model output. As an example, in one of the runs with module 2PG285 with water as the solvent (Table 10), the inlet and outlet gas volumetric flow rate are respectively 93.4 SCFH and 80.3 SCFH. The experimental value for $\mathrm{CO}_{2}$ removal for this test case DE-FE-0000646 Final Technical Report 
is about $42 \%$. The output of the model using the inlet, outlet and average (86.9 SCFH) gas flow conditions are about $39 \%, 43 \%$ and $41 \%$ respectively.

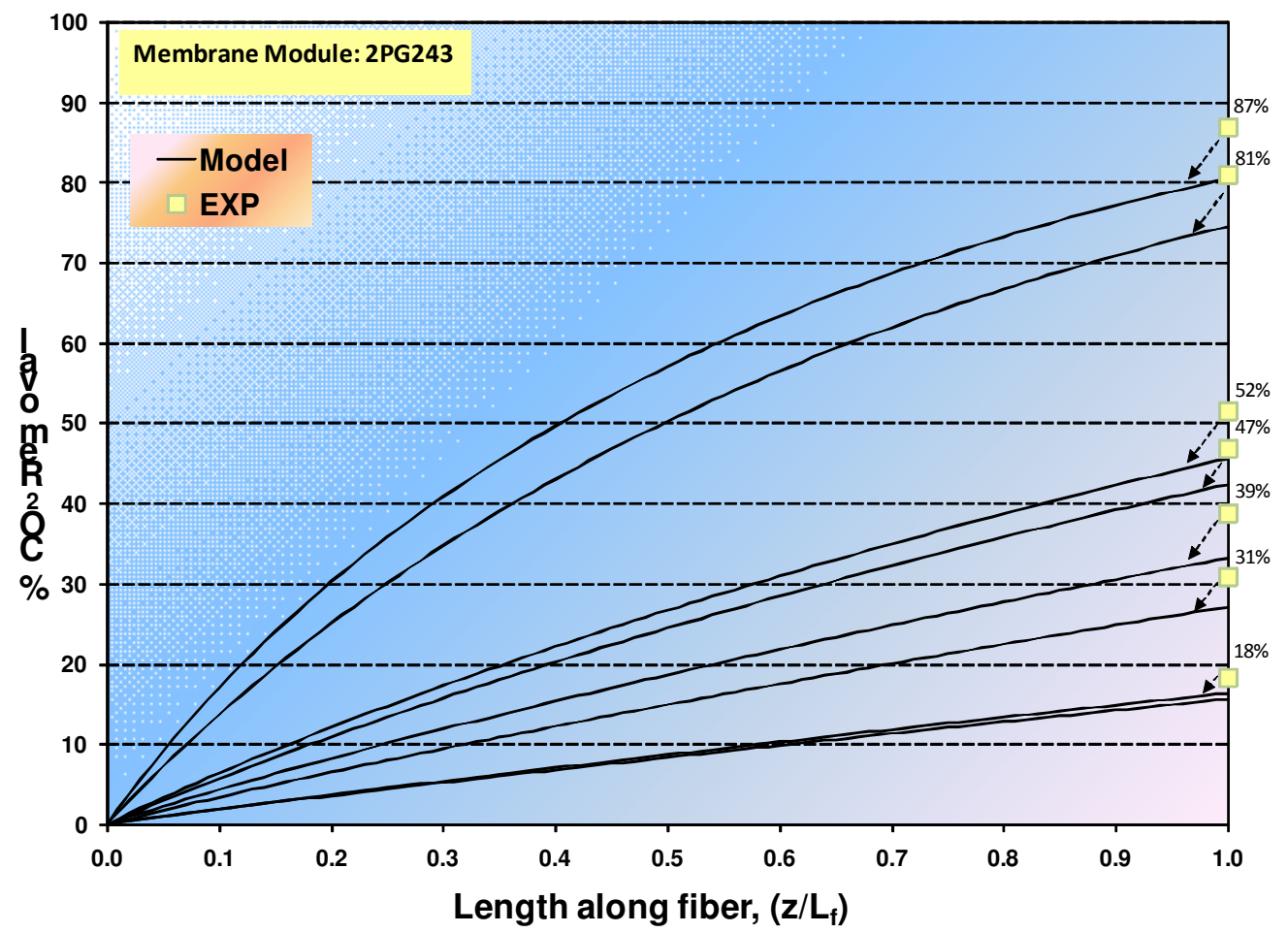

Figure $30 \mathrm{CO}_{2}$ removal along length of fiber with water as solvent: Module 2PG243 


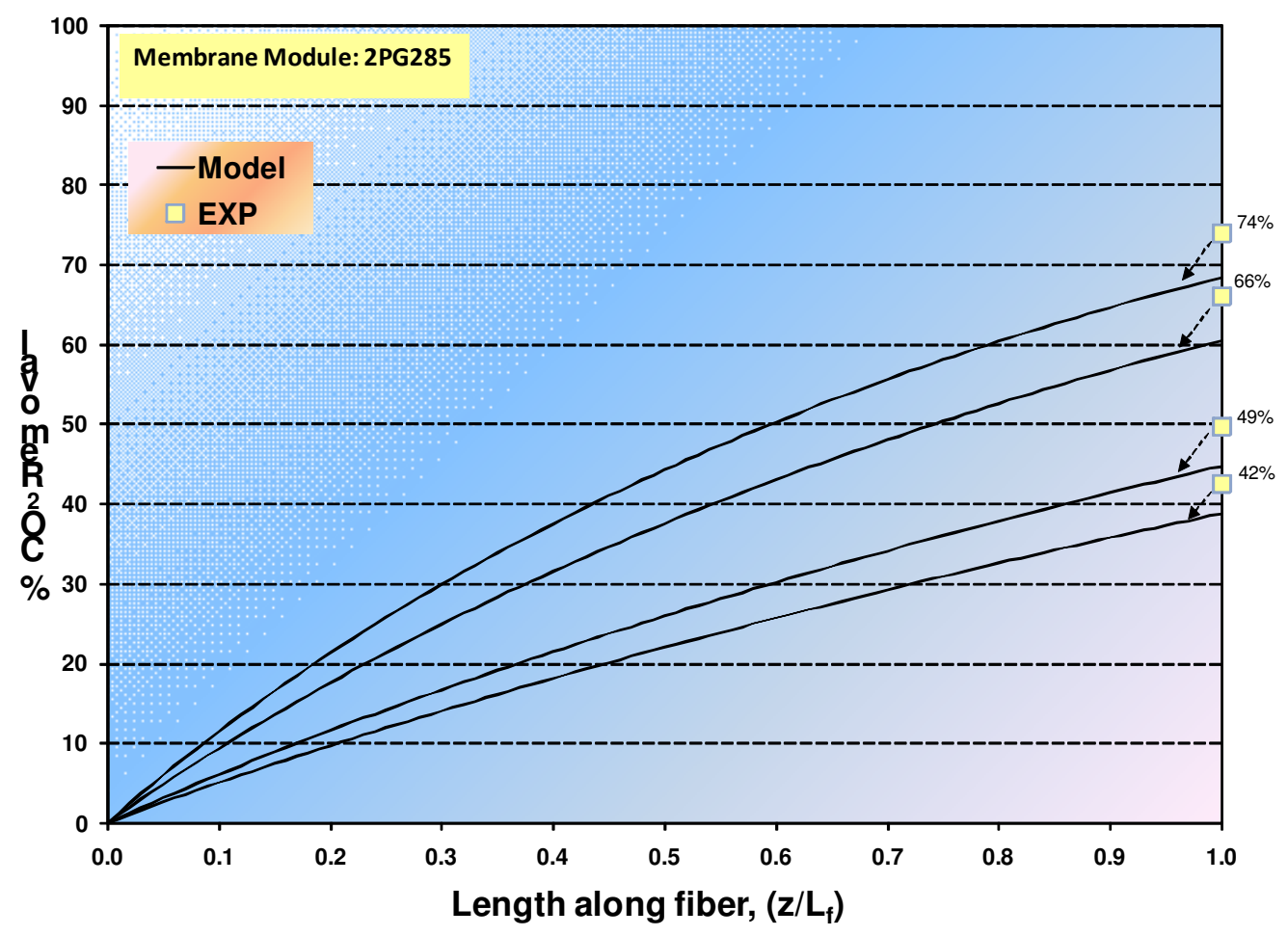

Figure $31 \mathrm{CO}_{2}$ removal along length of fiber with water as solvent: Module 2PG285

The model uses a constant overall mass transfer coefficient $\left(\mathrm{K}_{\mathrm{ov}}\right)$ that can be estimated or user specified. In the comparisons, the experimental overall mass transfer coefficient is used in the model prediction. The experimental mass transfer coefficients are given in Table 11 and table 13 for the two modules 2PG243 and 2PG285. A number of mass transfer correlations exist in the literature for predicting the shell side mass transfer coefficient ${ }^{10,11}$ (Lipnizki and Field, 2001, Keshavarz et al., 2008). It was seen that estimated overall mass transfer coefficient is dependent on the choice of correlation. Table 19 compares the experimental and estimated overall mass transfer coefficient using literature correlations.

Table 19: Comparison of experimental and estimated overall mass transfer coefficient

\begin{tabular}{|l|l|l|}
\hline Experimental $\mathrm{K}_{\mathrm{G}}, \mathrm{cm} / \mathrm{s}$ & $\begin{array}{l}\text { Estimated, } \mathrm{K}_{\mathrm{G}}, \mathrm{cm} / \mathrm{s} \\
\text { Dahuron and Cussler (1988) }\end{array}$ & $\begin{array}{l}\text { Estimated } \mathrm{K}_{\mathrm{G}}, \mathrm{cm} / \mathrm{s} \\
\text { Lipnizki and Field (2001) }\end{array}$ \\
\hline $8.9 \times 10^{-3}$ & $5.73 \times 10^{-3}$ & $1.52 \times 10^{-3}$ \\
\hline $7.8 \times 10^{-3}$ & $5.73 \times 10^{-3}$ & $1.52 \times 10^{-3}$ \\
\hline $9.3 \times 10^{-3}$ & $4.49 \times 10^{-3}$ & $1.49 \times 10^{-3}$ \\
\hline $11.1 \times 10^{-3}$ & $4.49 \times 10^{-3}$ & $1.50 \times 10^{-3}$ \\
\hline
\end{tabular}

DE-FE-0000646 Final Technical Report 
The overall mass transfer coefficient is estimated based on the series resistance approach as mentioned before. As seen from the above table, the experimental overall mass transfer coefficient is higher compared to the estimated ones. It may be due to the fact that in addition to axial flow along fibers, there could be stream splitting which provides transverse flow across fibers as fluid continuously seeks preferential paths due to heterogeneity in packing ${ }^{12}$ (Costello et al., 1993). The estimation of the individual resistances also showed that the transport process is liquid phase controlled.

\section{Briefings/technical presentations}

Project Activities/Products: A project overview including project objectives, project schedule and budget was presented at a project kickoff meeting at the National Energy Technology Laboratory in Pittsburgh, PA on November 13, 2009. Material on this work was presented at the Ninth Annual Carbon Capture and Sequestration Conference, May 10-13, 2010, Pittsburgh, PA in a poster session, entitled "CarboLock Process for $\mathrm{CO}_{2}$ Capture" and at the $4^{\text {th }}$ International Freiberg Conference on IGCC and XtL Technologies, May 3-5, 2010, Dresden, Germany in a presentation, entitled "Advanced $\mathrm{H}_{2} \mathrm{~S}$ and $\mathrm{CO}_{2}$ Removal Technologies for Synthesis Gases."

\section{CONCLUSIONS AND RECOMMDATIONS}

GTI and PGC have demonstrated in bench-scale testing a nanoporous and superhydrophobic PEEK-based hollow fiber membrane contactor technology for the membrane contactor/solvent absorption application in syngas cleanup. The feasibility of membrane contactor module scaled up to commercial size modules has been demonstrated (8-inch diameter by 5 foot long). We have performing extensive laboratory and bench-scale testing of membrane contactors with physical solvents using simulated syngas stream, and a slipstream from a gasification-derived syngas at GTI's Flex-Fuel Test Facility (FFTF) gasification plant under commercially relevant operating process conditions. The team have also carried out an engineering and economic analysis of the membrane contactor process to evaluate the economics of this technology and its commercial potential.

Our test results have shown that $90 \% \mathrm{CO}_{2}$ capture can be achieved with several physical solvents such as water and chilled methanol. The rate of $\mathrm{CO}_{2}$ removal by the membrane contactor is in the range of 1.5 to $8.0 \mathrm{~kg} / \mathrm{m}^{2} / \mathrm{hr}$ depending on the operating pressure, temperature and solvent selection. The economic analysis has shown that the membrane contactor process will cause the cost of electricity to increase by $21 \%$ from the base plant without $\mathrm{CO}_{2}$ capture. The goal of $10 \%$ increase in levelized cost of electricity (LCOE) from the base DOE Case 1 (base plant without capture) was not achieved using the membrane contactor technology. However, the $21 \%$ increase in LCOE was a substantial improvement as compared to the $31.6 \%$ increase in LCOE as in DOE Case 2 (state of art capture technology using 2-stages of Selexol ${ }^{\mathrm{TM}}$ ). The work has indicated a substantial further improvement in $\mathrm{CO}_{2}$ removal efficiency and thus overall process economics can be obtained by improving contactor module structured packing configurations. The hollow fiber structured packing must be optimized toward specific solvent systems for optimum performance.

Therefore, GTI and PGC recommend further development work needs to be conducted to capture the promise of this technology. Specifically, the membrane contactor technology needs to be optimized to reduce cost of the process by 1) optimize the PEEK hollow fiber membrane and DE-FE-0000646 Final Technical Report 
structured packing of the hollow membrane for improved mass transfer coefficient, and 2) pilot testing at a larger scale to further the technology readiness level for possible commercialization in the future when the need arises for pre-combustion carbon capture.

\section{REFERENCES}

1. "Evaluation of Innovative Fossil Fuel Power Plants with $\mathrm{CO}_{2}$ Removal," DOE/EPRI, 100316, Dec. 2000.

2. DOE/NETL-2007/1281 "Cost and Performance Baseline for Fossil Energy Plants" Volume 1: Bituminous Coal and Natural Gas to Electricity Final Report (Original Issue Date, May 2007), Revision 1, August 2007.

3. US Patent 6,887,408, May, 2005.

4. US Patent 7,176,273, Feb., 2007.

5. Yampolskii, Y. et al. Materials Science of Membranes for Gas and Vapor Separation, John Wiley and Sons, 2006.

6. Baker, R. W., Membrane Technology and Applications, $2^{\text {nd }}$ ed., John Wiley \& Sons Ltd., Chichester, England, 2004, p. 544.

7. Feng, et al., Adv. Mater., 2002, 14, p.1857.

8. Hoff, K. A., Modeling and Experimental Study of Carbon Dioxide Absorption in a Membrane Contactor, PhD Thesis, Norwegian University of Science and Technology, March 2003.

9. Lipnizki, F and R.W. Field, 2001. Mass transfer performance for hollow fiber modules with shell-side axial feed flow: using an engineering approach to develop a framework, $J$. Memb. Sci., 193, 195-208.Costello, M.J., Fane, A.G., Hogan, P.A and R.W. Schofield, 1993.The effect of shell side hydrodynamics on the performance of axial flow hollow fiber modules, . J. Memb. Sci., 80, 1-11.

10. Keshavarz, P., Ayatollahi, S. and J. Fathikaljahi, 2008. Mathematical modeling of gas-liquid membrane contactors using random distribution of fibers, J. Memb. Sci., 325, 98-108.

11. Penttilä, A., Dell'Era, C., Uusi-Kyyny, P., and V. Alopaeus, 2011. The Henry's Law Constant of $\mathrm{N} 2 \mathrm{O}$ and $\mathrm{CO} 2$ in Aqueous Binary and Ternary Amine Solutions (MEA, DEA, DIPA, MDEA, and AMP), Fluid Phase Equil., 311, 59-66.

12. Dahuron, L. and E L Cussler, 1988. Protein extractions with hollow fibers, AIChE J, 34, 130-136. 


\section{LIST OF ACRONYMS AND ABBREVIATIONS}

aMDEA: activated methyldiethanolamine

COE: cost of electricity

D.I.: Deionized Water

DOE: U.S. Department of Energy

FFTF: Flex Fuel Test Facility (at GTI)

GTI: Gas Technology Institute

IGCC: Integrated Gasification Combined Cycle

MDEA: methyldiethanolamine

NETL: National Energy Technology Laboratory

P\&ID: piping and instrumentation diagram

PEEK: poly (ether ether ketone)

PEI: polyether imide

PGC: PoroGen Corporation

PI: Principal Investigator

WGS: Water Gas Shift

\section{NOMENCLATURE}

$a_{b}-$ specific surface area of fibers based on bundle volume, $\mathrm{m}^{2} / \mathrm{m}^{3}$

$a_{m}$ - specific surface area of fibers based on module volume, $\mathrm{m}^{2} / \mathrm{m}^{3}$

$A_{b}-$ cross sectional area of bundle, $(\pi / 4)\left(D_{2}{ }^{2}-D_{1}{ }^{2}\right), m^{2}$

$\mathrm{A}_{\mathrm{m}}$ - cross sectional area of module, $(\pi / 4) \mathrm{D}_{3}{ }^{2}, \mathrm{~m}^{2}$

$\mathrm{C}_{\mathrm{i}, \mathrm{g}}$ - gas phase species concentration, $\mathrm{mol} / \mathrm{m}^{3}$

$\mathrm{C}_{\mathrm{i}, \mathrm{I}}$ - liquid phase species concentration, $\mathrm{mol} / \mathrm{m}^{3}$

$\mathrm{H}_{\mathrm{i}}$ - dimensionless Henry's law constant

$K_{o v}$ - overall mass transfer coefficient

$L_{b}$ - Active bundle length, $\mathrm{m}$

$n_{f}-$ number of fibers

$\mathrm{U}_{\mathrm{g}}$ - average gas velocity, $\mathrm{m} / \mathrm{s}$

$\mathrm{U}_{1}$ - average liquid velocity, $\mathrm{m} / \mathrm{s}$

DE-FE-0000646 Final Technical Report 
$\mathrm{z}$ - active fiber length, $\mathrm{m}$

$\varepsilon_{b}$ - bundle porosity

$\varepsilon_{g A}$ - fractional area available for gas flow in the bundle, $1-\varepsilon_{b}$

$\mathrm{z}$ - active fiber length, $\mathrm{m}$

$\varepsilon_{l A}$ - fractional area available for liquid flow in the membrane bundl 